\title{
Araştırma-Sorgulamaya Dayalı Öğretime Yönelik Akademik Çalışmaların Bibliyometrik Analizi (2000- 2020)
}

\author{
DOI: $10.26466 /$ opus. 865502 \\ Tolga Saka * - Tufan İnaltekin** \\ * Dr. Öğr. Üyesi, Kafkas Üniversitesi, Kars/Türkiye \\ E-Posta: tsaka61@gmail.com \\ ORCID: 0000-0002-0042-0836 \\ ** Dr. Öğr. Üyesi, Kafkas Üniversitesi, Kars/Türkiye \\ E-Posta: inaltekintufan@gmail.com \\ ORCID: $\underline{0000-0002-3843-7393}$
}

Öz

Bu çalışma, Web of Science (WoS) veri tabanında yer alan araştırma sorgulamaya dayalı öğretim (ASDÖ) yaklaşımına yönelik son yirmi yıldaki akademik çalışmaların bibliyometrik analizini yapmayı amaçlamaktadır. Bu amaçla WoS veri tabanında indekslenen 264 ASDÖ çalışması bibliyometrik özellikleri açısından incelenmiş ve VOSviewer programı kullanılarak ă̆ haritası ortaya çıkarılmıştır. ASDÖ çalışmaları, atıf, bibliyografik eşleştirme, ortak atıf, ortak yazarlılı ve birlikte bulunma yapıları bakımından dokümanlar, kaynaklar, yazarlar, kurumlar ve ülkelere göre analiz edilmiştir. Sonuçlar, "inquiry-based learning (sorgulamaya dayal öğrenme)", "motivation (motivasyon)" ve "science education (fen bilimleri eğitimi)" terimlerinin en çok kullanilan anahtar kelimeler olduğunu göstermiştir. ASDÖ'ye ilişkin en çok atıf alan çalışmanın "Spronken-Smith ve Walker (2010)", en aktif kaynağın "International Journal of Science Education" ve atıf sayısı en yüksek kaynağın ise "Studies in Higher Education" olduğunu göstermiştir. Ayrıca çalışmaların çoğunlukla İngiltere ve ABD'de yayınlandığı da görülmüştür. Yine çalışmaların 2013 yılından sonra Türkiye, Finlandiya ve Almanya'da yoğunluk kazandı̆̆ı ortaya çıkmıştır. Bu çalışmanın, ASDÖ konusunda çalışacak yeni araştırmacılar için, alandaki eğilimleri belirlemek ve konuyla ilgili mevcut araştırmaları karşılaştırmak için bir rehber olacağı düşünülmektedir.

Anahtar Kelimeler: Araştırma-sorguma temelli öğretim, bibliyometrik analiz, VOSviewer . 


\title{
Bibliometric Analysis of Academic Studies Regarding Inquiry-Based Teaching (2000- 2020)
}

\begin{abstract}
This study aims to conduct a bibliometric analysis of academic studies in the last two decades on inquirybased teaching (IBT) in the Web of Science (WoS) database. For this purpose, 264 ASDÖ studies indexed in the WoS database were examined in terms of their bibliometric properties and the network map was created using the VOSviewer program. ASDÖ studies were analyzed according to documents, sources, authors, institutions and countries in terms of citation, bibliographic matching, co-citation, co-authorship and coexistence structures. The results showed that "inquiry-based learning", "motivation" and "science education" were the most used keywords. It has shown that the most cited study on ASDÖ is "Spronken-Smith and Walker (2010)", the most active journal is "International Journal of Science Education", and the journal with the highest number of citations is "Studies in Higher Education". It was also seen that the studies were mostly published in the UK and USA. It has also been revealed that the studies have intensified in Turkey, Finland and Germany after 2013. It is thought that this study will serve as a guide for new researchers who will work on ASDÖ to identify trends in the field and to compare existing research on the subject.
\end{abstract}

Keywords: Inquiry-based teaching, bibliometric analysis, VOSviewer. 


\section{Giriş}

Araştırma sorgulamaya dayalı öğretim (ASDÖ), Dewey'in bilimsel düşünme becerilerinden etkilenerek yapılandırmacı öğretim yaklaşımı kapsamında ortaya çıkmıştır (Degenhart, 2007). ASDÖ’de, öğrencilerin problem çözmelerinden daha çok araştırma sürecine odaklanmaları ve araştırma becerilerinin geliştirilmesine önem verilmektedir (Lim, 2001). Aynı zamanda ASDÖ sürecinde öğrencilerin öğrenmeyi öğrenmeleri de amaçlanmaktadır (Shih, Chuang and Huang, 2010). ASDÖ, öğrencilerin sorulara geçici çözüm yolları tasarladığı, veriler topladığı ve bu verileri değerlendirerek sonuca ulaşmaya çalıştı̆̆ öğrenci merkezli bir öğretim olarak ifade edilmektedir (Chan, 2007; Fleissner, Chan, Yuen and $\mathrm{Ng}$, 2006). Bu öğretimin uygulandığı sinıflarda sorular genellikle gerçek hayattan senaryolar yardımı ile öğrencilere sunulmaktadır (Kahn and O'Rourke, 2005). ASDÖ öğrencilerin, derse karşı motivasyonunu arttırmalarını, bilgiyi zihinlerinde yapılandırarak kalıcı ve anlamlı öğrenmeler gerçekleştirmelerini, bilimsel araştırma yöntemlerini kullanmalarını ve eleştirel düşünme becerilerini geliştirmelerini sağlamaktadır (Schroeder, Scott, Tolson, Huang ve Lee; Wilke and Straits, 2005; Yıldız, 2013). Bu kapsamda, Dewey öğrencilerin öğrenmede aktif rol oynadıkları ASDÖ'nün, fen bilimleri öğretim programına yerleştirilmesi gerekliliğini belirtmiştir (Barrow, 2006). ASDÖ, 19. yüzylldan itibaren öğretim programlarında yer almaya başlamıştır (DeBoer, 2000). Türkiye'de ise 2013 yılında Fen Bilimleri Dersi öğretim programı ASDÖ’ye göre yeniden biçimlendirilmiştir (MEB, 2013). Alanyazın incelendiğinde ASDÖ ile ilgili ulusal ve uluslararası düzeyde yapılan çalışmaların sayısının her geçen gün arttığ görülmektedir (Almuntasheri, Gillies and Wright, 2016; Minner, Levy and Century, 2010; Saka, 2018).

ASDÖ ile ilgili yapılan çalışmalar incelendiğinde, bu çalışmaların ASDÖ'nün etkisi, araştırma sorgulamaya dayalı mesleki gelişim programlarının etkisi ve ASDÖ uygulamaları olarak üç ana konuda gerçekleştiği görülmektedir. Ayrıca ASDÖ'nün etkisine yönelik yapılan çalışmaların öğretmen, öğretmen adayı ve öğrenci grupları üzerinde gerçekleştirildiği de ön plana çıkmaktadır (Saka, 2018; Saka, Akcanca, Kala Aydın ve Sungur Alhan, 2018). ASDÖ'nün etkisine yönelik çalışmalar incelendiğinde, öğretmenlerin ASDÖ'nün etkisi ile kavram bilgilerinin (Lee ve diğ., 2004) ve bili- 
min doğasına yönelik görüşlerinin (Akerso, Hanson and Cullen, 2007; Parrish, 2017) geliştiği sonucuna varılmıştır. Benzer şekilde öğretmen adaylarının akademik başarılarının arttığı (Sarı ve Güven, 2013; Yetişir, 2016), yaklaşıma dair bilgi sahibi oldukları (Akcanca,2020), ASDÖ hakkındaki öz yeterlilik inançları (Kayacan, 2014; Özdilek ve Bulunuz, 2009; Soprano and Yang, 2013) ve bilimsel süreç becerilerini kullanma düzeylerinin geliştiği de (Duru, Demir, Önen, ve Benzer, 2011) ön plana çıkmıştır. Öğrencilerin ise akademik başarılarının arttığı (Kaya ve Yılmaz, 2016; Minner vd., 2010; Ören Şaşmaz ve Sarı, 2017; Tse and Kuhlthau, 2008; Vlassi and Karaliota, 2013), eleştirel düşünme ve problem çözme becerilerinin (Di Pasquale, Mason and Kolkhorst, 2003; Kowalczyk, 2003), kavram bilgilerinin (Almuntasheri ve diğ., 2016; Ireland, Watters, Brownlee and Lupton, 2014; Rethinam and Lynch, 2011) ve bilimsel süreç becerilerinin geliştiği (Bunterm, Lee, Ng Lan Kong, Srikoon, Vangpoomyai, Rattanavongsa and Rachahoon, 2014; Çelik, 2012; Duran, 2015; Hsin-Kai Wu and Chou-En Hsieh, 2006; Kaya ve Yllmaz, 2016; Şimşek and Kabapınar, 2010) sonucuna varılmıştır.

Araştırma sorgulamaya dayalı mesleki gelişim programlarının etkisini belirlemeye yönelik yapılan çalışmalar incelendiğinde, bu programlara katılan öğretmenlerin araştırma sorgulama becerilerinin geliştiği (Basista, Tomlin, Pennington and Pugh, 2001; Hairida, 2016; Wee, Shepardson, Fast and Harbor, 2007), bu öğretimi uygulamaya yönelik güvenlerinin (Açkgöz, 2019; Basista vd., 2001; Lotter, Harwood and Bonner, 2006) ve düşüncelerinin (Luft, 2001; Nam, Seung and Go, 2013; Usta, 2015) olumlu yönde değiştiği tespit edilmiştir. Benzer şekilde bu programlara katılan öğretmen adaylarının da ASDÖ'yü uygulamaya yönelik (Ann Haefner and Zembal-Saul, 2004; Varma, Volkmann and Hanuscin, 2009) ve bu öğretim kapsamında derslerde gerekli olan araştırma sorularını sormaya yönelik (Varma vd., 2009) anlayışlarının geliştiği sonucu ortaya çıkmıştır.

Öğretmen ve öğretmen adaylarının ASDÖ'ü uygulama düzeylerine yönelik birçok çalışma bulunmaktadır. Bu çalışmalar incelendiğinde, öğretmenlerin bu öğretim hakkında bilgilerinin olmadığı (Alkış Küçükaydın, 2017; Atila ve Sözbilir, 2016; Bölme, 2019; Murphy, Kilfeather and Murphy, 2007; Staer, Goodrum and Hackling, 1998), ASDÖ'ü uygulamaya karşı mesleki kaygilarının olduğu (Kapanadze, Bolte, Schneider and Slovinsky, 2015) ön plana çıkmıştır. Benzer şekilde öğretmen adaylarının da bu öğretimi uygulamaya yönelik ilgilerinin düşük olduğu (Chabalengula and Mumba, 
2012) ve ASDÖ’yü istenilen seviyede uygulayamadıkları (Akcanca, 2020; Arslan, Ogan Bekiroğlu, Süzük ve Gürel, 2014) sonucuna varılmıştır. Aynı zamanda öğretmen ve öğretmen adaylarının ASDÖ uygulama düzeylerini geliştirmek için eğitimler verilmesi gerektiği ön plana çıkmıştır (Van-Uum, Verhoeff and Peeters, 2016).

ASDÖ ile ilgili yapılan çalışmalar incelendiğinde, bu öğretimin öğretmen, öğretmen adayı ve öğrenciler üzerinde birçok olumlu etkisinin (Bunterm ve diğ., 2014; Hairida, 2016; Parrish, 2017) olmasına rağmen öğretmen ve öğretmen adaylarının bu yaklaşımı uygulamada birçok eksikliklerinin olduğu (Arslan ve diğ., 2014; Kapanadze ve diğ., 2015) görülmektedir. Bu bağlamda ASDÖ ile ilgili yapılan çalışmaların incelenmesinin, bu konuda yeni çalışmalara başlayacak araştırmacılar için yol gösterici nitelikte olacağı söylenebilir. Bu çalışmanın alan yazındaki diğer çalışmalardan farklı olarak ASDÖ ile ilgili 2000-2020 yılları arasında yapılan makalelerin sosyal ağ analizini ortaya çıkarmış olması nedeniyle alanyazına farklı bir katkı sunacağı düşünülmektedir. Bu bağlamda çalışmanın, ASDÖ konusundaki arka planı okumaya ve orijinal yayınların saptanmasına, kişilerin, ülkelerin ve kurumların ASDÖ yayınları konusundaki verimliliklerinin gösterilmesine rehberlik yapacağ 1 ifade edilebilir.

\section{Araștırmanın Amacı ve Soruları}

Bu çalışmada, ASDÖ’ye yönelik son yirmi yıldaki (2000-2020) akademik çalışmaların bibliyometrik analizinin yapılması amaçlanmıştır. Bu kapsamda cevabı aranan sorular şunlardır:

(1) ASDÖ'ye ilişkin yayınların atıf sayılarının dokümanlar, kaynaklar, yazarlar, kurumlar ve ülkelere göre dağılımı ve ağ haritası nasıldır?

(2) ASDÖ’ye ilişkin yayınların bibliyografik eşleştirmesinin, dokümanlar, kaynaklar, yazarlar, kurumlar ve ülkelere göre ağ haritası nasıldır?

(3) ASDÖ'ye ilişkin yayınların ortak atıflarının, alıntı yapılan referanslar, kaynaklar ve yazarlara göre ağ haritası nasıldır?

(4) ASDÖ'ye ilişkin yayınların ortak yazarlıklarının yazarlar, kurumlar ve ülkelere göre ağ haritası nasıldır?

(5) ASDÖ'ye ilişkin yayınların anahtar kelimeler ağ haritası nasıldır? 


\section{Yöntem}

\section{Araștırmanın deseni}

$\mathrm{Bu}$ araştırma, nicel araştırma yöntemlerinden betimsel araştırma desenini içermektedir. Betimsel araştırmalarda, bir veri setinin daha anlamlı hale getirilmesi ve temel özelliklerinin başkaları tarafından da kolayca anlaşılabilmesi sağlanır (Christensen, Johnson and Turner, 2014) Bu bağlamda, ASDÖ konusundaki araştırmaların durumunu keşfetmek için bibliyometrik yaklaşım kullanılmıştır. Bibliyometrik çalışmalar, belirli bir alandaki araştırmanın bazı özelliklerini ölçerek ve sonuçları değerlendirerek bu alandaki eğilimlerin belirlenmesine izin vermektedir (Kasemodel, Makishi, Souza and Silva, 2016). Bu çalışmalar, bir alanın veya disiplinin gelişim modellerinin güçlü bir öngörücüsü, yayınlardaki ve alıntılardaki eğilimleri içerir (Hernandez, Torrano and Ibrayeva, 2020). Bibliyometrik yöntem, bir alandaki bilimsel araştırmaların sınırlarını belirtmek için istatistiksel yöntemlerin kullanmasını içermektedir (Pan, Jian and Liu, 2019). Bibliyometrik çalışmalar, bir araştırma alanının genel görünümü ve önde gelen araştırmaçların analizini ortaya koymak için yapılmaktadır (Bjork, Offer and Söderberg, 2014). Belirli bir alanda yayınlanan çalışmaların belirli göstergelerini nicel olarak analiz etmek ve büyük bir veri tabanı temelinde bilgi haritaları oluşturmak için bibliyometrik analiz uygulanmaktadır (Zeng and Chini, 2017). Bu kapsamda çalışmada, Web of Science (WoS) veritabanından çekilen 20 yıllık (2000-2020) ASDÖ araştırma literatürü için bibliyometrik yöntem uygulanmıştır. Bu çalışmanın işlem basamakları Şekil 1'de gösterilmiştir. 


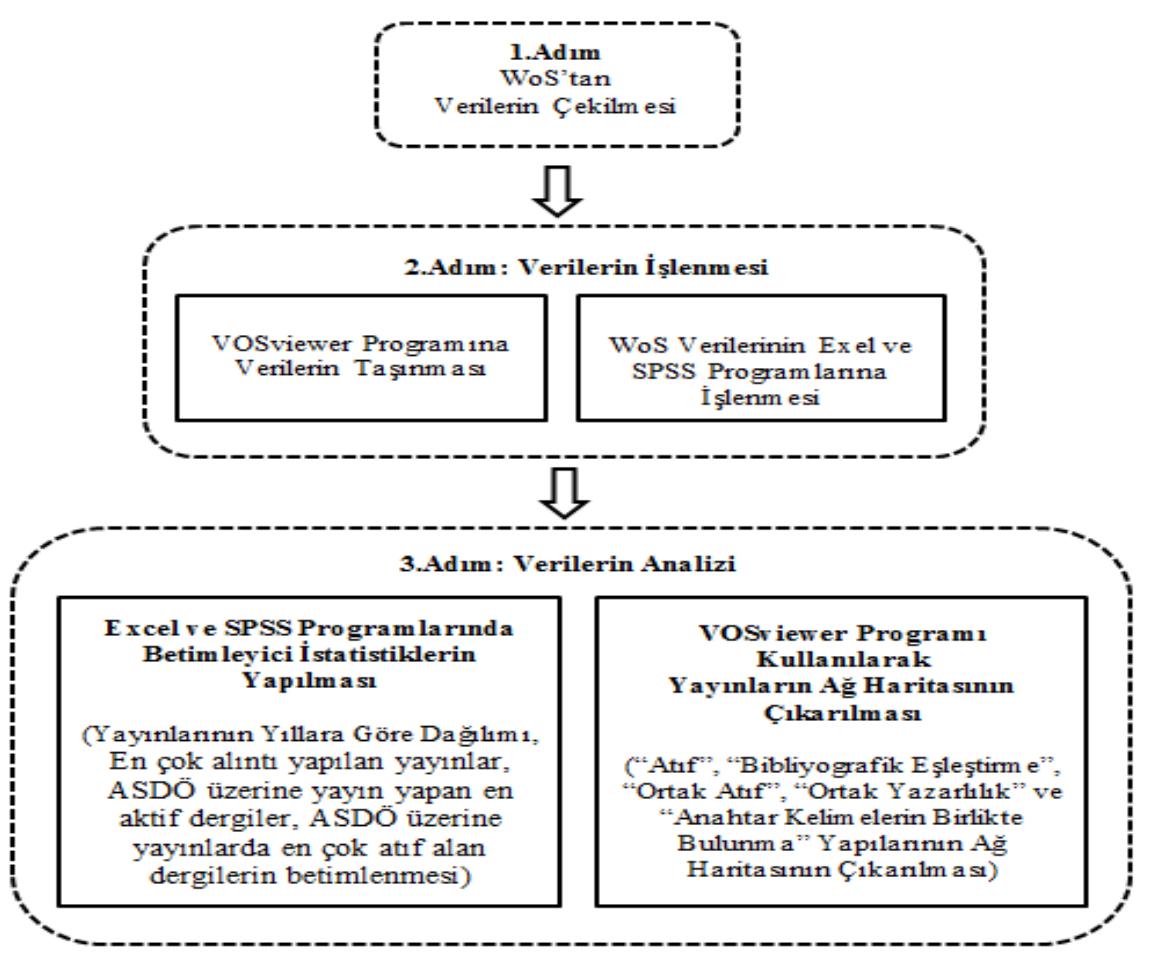

Şekil 1. Çalışmanın işlem basamaklan

\section{Veri kaynakları}

Bu çalışmada WoS veritabanı araştırmanın örneklemi için bir bibliyometrik veri kaynağı olarak kullanılmıştır. Taramanın WoS veri tabanında yapılmasının nedeni, tüm bilim dünyası tarafından kullanılan ve akademik yükselmelerde kabul gören bir veri tabanı olmasıdır (Gürlen, Özdiyar ve Şen, 2019). 13 Ekim 2020 tarihinde, WoS veritabanında anahtar kelime olarak "Inquiry-Based Learning" ifadesi aranmış ve bu kalıbı içeren 264 akademik yayına ulaşılmıştır. Bu çalışmların 248'i İngilizce, 11'i Çekçe, 2'si İspanyolca ve $3^{\prime}$ ü ise Türkçe yayın diline sahiptir. Çalışmanın veri kaynaklarını içeren ayrıntılı parametreler Grafik 1'de verilmiştir.

Grafik 1'de bu çalışma için seçilen dökümanların türü yer almaktadır. WoS üzerinden elde edilen 264 çalışmanın türü incelendiğinde \%74'nün (n=195) makale, \%22'sinin (n=58) kitap bölümü, \%3'nün $(n=7)$ erken görünüm makale ve \%1'nin (n=4) ise konferans bildirisinden oluştuğu görülmektedir. 


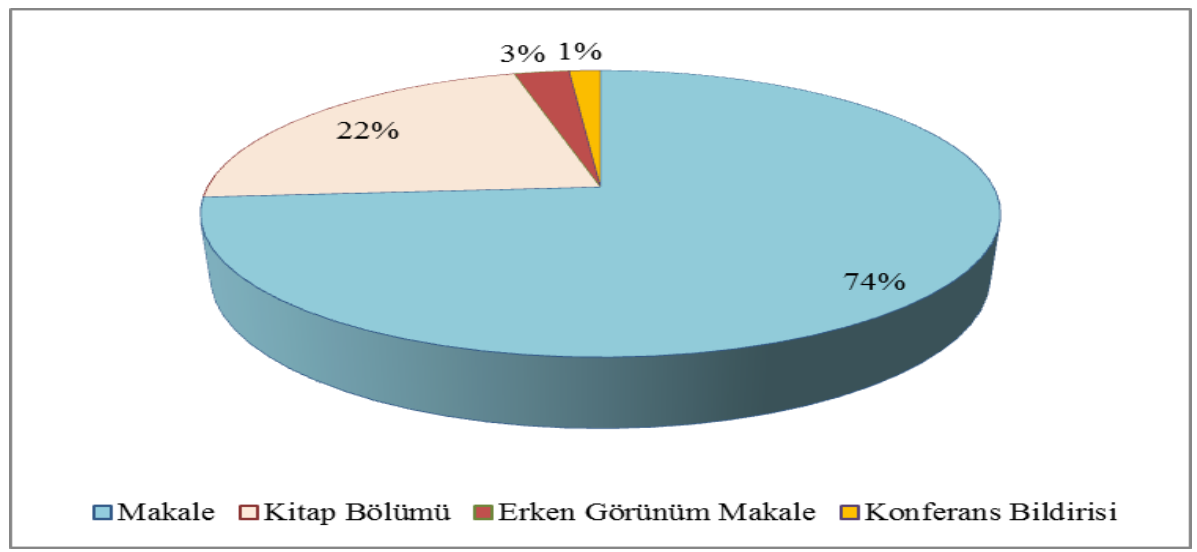

Grafik 1. Çalışmanın veri kaynağına dâhil edilen dökümanların yayın türü

\section{Verilerin toplanmasi}

WoS, multidisipliner yapıya sahip tek veri tabanı olması nedeniyle dünya genelinde yaygin olarak kullanılmaktadır (Zancanaro, Todesco and Ramos, 2015). ASDÖ konusunda yapılan akademik çalışmalar, WoS veri tabanına "inquiry-based learning " anahtar sözcügü girilerek çekilmiştir. Bu kapsamda WoS veri tabanında Science Citation Index Expanded (SCI-EXPANDED), Social Sciences Citation Index (SSCI), Arts and Humanities Citation Index (AHCI), Conference Proceedings Citation Index ve Emerging Sources Citation Index (ESCI) dizinleri seçilmiş, ayrıca taramada yıl sınırlamasına gidilerek 2000-2020 tarih aralığ1 işlenmiştir. Bu işlemlerin ardından 264 çalışmanın bibliyografik verilerine ulaşılmış ve bu veriler kaydedilmiştir.

\section{Verilerin analizi}

Genel olarak bir bibliyometrik analiz, her araştırma alanının yazarlar, anahtar kelimeler, başlıklar ve özetlerden, terimler, alıntılar ve referanslar gibi meta verilerin toplanmasıdır ( $\mathrm{Li}$, Antonenko and Wang, 2019). Bibliyometrik analizler, mevcut araştırmayı organize etmeyi amaçlayan nicel prosedürlere dayanmaktadır. Bu analiz yöntemi, belirlenen bilimsel konu ile ilgili çalışmaların, araştırmacıların, kurumların ve bilimsel akışların takibini sağlar (MartíParreño, Méndez-lbáñez and Alonso-Arroyo, 2016). Bibliyometrik analiz, birçok çalışmada araştırma performansının değerlendirilmesi için kullanılan 
kitaplar veya makaleler gibi yazılı yayınları içeren yaygın bir istatistiksel prosedürdür (Eduan and Yuanqun, 2019). VOSviewer, iki döküman arasındaki mesafeyi görselleştirmek için kullanışı bir araçtır ve bu iki dökümanın ilişki gücünü bibliyometirk bağlamda gösterir (bkz. www.vosviewer.com) (van Eck. and Waltman, 2010; van Eck and Waltman, 2011; van Eck and Waltman, 2014; van Eck, Waltman, Dekker and van den Berg, 2010). VOSviewer, mesafe tabanlı haritalamayı mümkün kılar; bu, birbirine yakın olan iki merkez noktanın birbirlerinden daha uzak olanlardan daha yüksek derecede bir korelasyon sergilediğini gösterir (Waltman and van Eck, 2009; Robertson, Pitt and Ferreira, 2020). VOSviewer ayrica doğrudan birbiriyle ilişkili olan merkez noktaları bağlar ve farklı kümeleri kolayca tanımlamak için farklı renkler kullanır (Lam, Feng, Treen and Ferreira, 2020). Bu çalışmanın verileri, Excel, SPSS 18 ve VOSviewer programları kullanılarak analiz edilmiştir. Yayın ve atıf verilerinin analizi, son 20 yılda ASDÖ araştırmalarının büyüme yörüngesini tanımlamak için yapılmıştır. $\mathrm{Bu}$ kapsamda WoS veri tabanından bilgisayara indirilen bibliyometrik verilerin ilk önce Excel programında düzenlemesi yapılmış, ardından bu veriler SPSS 18 programına taşınarak betimleyici analizleri yapılmıştır. Bu betimleyici analizler, ASDÖ alanında yayın ve atıf sayısı bakımından önde gelen yazarları, yayın türlerini ve ülkeleri ortaya çıkarmıştır. Çalışmamızda bibliyografik materyalin haritasını çıarmak için VOSviewer yazılımı www.vosviewer.com adresinden ücretsiz olarak temin edilmiştir. Daha sonra VOSviewer programı kullanılarak 264 yayının sosyal ağ haritalaması yapılmıştır. Bu bağlamda ASDÖ çalışmalarının "atıf (citation)", "bibliyografik eşleştirme (bibliographic-coupling)", "ortak atıf (co-citation)", "ortak yazarlılık (co-authorship)" ve "birlikte bulunma (co-occurrence)" yapılarının, dokümanlar, kaynaklar, yazarlar, kurumlar ve ülkelere göre ağ haritası çıkarılmıştır. Bu kavramlardan, "atıf analizi", bir belgenin başka bir belgede bahsedilme durumunun (Franceschini, Maisano and Mastrogiacomo, 2015; Kim and McMillan, 2008; Smith, 1981; Yu and Shi, 2015); "'bibliyografik eşleştirme analizi", bir ya da daha fazla refaransın, iki yayında ortak atıf yapılma durumunun (Freire and Verissimo, 2020; Kessler, 1963; Shah, Lei, Ali, Doronin and Hussain, 2019; van Eck and Waltman, 2017); "ortak atıf analizi", aynı yayından atıf almış belgelerin (Hou, Yang and Chen, 2018; Small, 1973; Trujillo and Long, 2018; White and McCain, 1998); "birlikte bulunma analizi", yayınlarda anahtar kelimelerin birlikte kullanımlarının (Cancino, Merigó, Coronado, 
Dessouky, and Dessouky, 2017; Laengle vd., 2017; Zhao, 2017) ve "ortak yazarlılık analizi", araştırmacıların ortak çalışmalar içerisinde bulunma durumlarının analiz edilmesidir (Chen, Yu, Cheng and Hao, 2019; Eaton, Ward, Kumar and Reingen, 1999).

\section{Bulgular}

Çalışmanın bulguları, ASDÖ yayınlarının "atıf", "bibliyografik eşleştirme", "ortak atıf", "ortak yazarlılık" ve "birlikte bulunma" yapılarının dokümanlar, kaynaklar, yazarlar, kurumlar ve ülkelere göre ağ haritası ve dağılımını içermektedir.

ASDÖ çalışmalarının 2000-2020 arasında yıllara göre yayın sayıları Grafik 2'de gösterilmiştir.

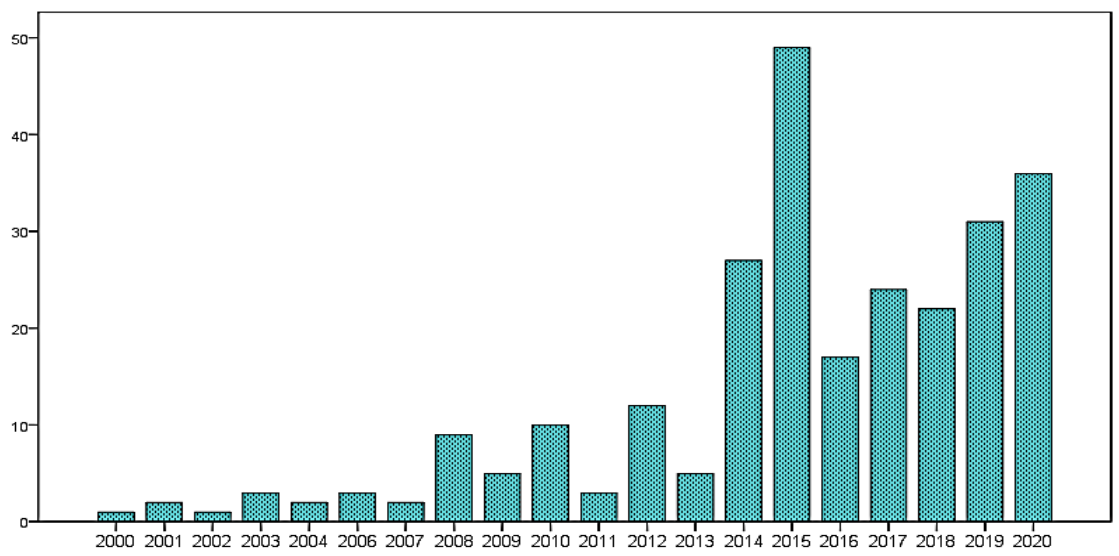

\section{Grafik 2. ASDÖ yayınlarının yıllara göre dă̆ılımı}

Grafik 2, 2000-2020 yılları arasında ASDÖ çalışmalarının yıllara göre yayın sayısı göstermektedir. Grafik 2 incelendiğinde ASDÖ çalışmalarının yıllar içinde dalgalanmalar sergilediği anlaşılmaktadır. Bununla birlikte ASDÖ çalışmalarının 2015 yılında zirve yaptığı, 2016 yılında ise ciddi düşüş sergilediği ve bu yıldan sonra yeniden istikrarlı bir yükselişe geçtiği görülmektedir.

En çok atıf alan ilk on ASDÖ çalışması Tablo 1'de gösterilmiştir 
Tablo 1. En çok alıntı yapılan on ASDÖ çalışması

\begin{tabular}{|c|c|c|c|c|}
\hline $\begin{array}{l}\text { Sira } \\
\text { No }\end{array}$ & Çalışmanın Adı & Yazar/lar & $\begin{array}{l}\text { Yayin } \\
\text { Ylli }\end{array}$ & $\begin{array}{l}\text { Atif } \\
\text { Sayis1 }\end{array}$ \\
\hline 1 & $\begin{array}{l}\text { Can inquiry-based learning strengthen the } \\
\text { links between teaching and disciplinary re- } \\
\text { search? }\end{array}$ & $\begin{array}{l}\text { Spronken-Smith, R; } \\
\text { Walker, R }\end{array}$ & 2010 & 98 \\
\hline 2 & $\begin{array}{l}\text { How do first-year university students experi- } \\
\text { ence inquiry and research, and what are the } \\
\text { implications for the practice of inquiry-based } \\
\text { learning? }\end{array}$ & Levy, P; Petrulis, R & 2012 & 94 \\
\hline 3 & $\begin{array}{l}\text { A contextual game-based learning approach to } \\
\text { improving students' inquiry-based learning } \\
\text { performance in social studies courses }\end{array}$ & $\begin{array}{l}\text { Hwang, GJ; Chiu, LY; } \\
\text { Chen, CH }\end{array}$ & 2015 & 79 \\
\hline 4 & $\begin{array}{l}\text { Inquiry-based learning in higher education: } \\
\text { principal forms, educational objectives, and } \\
\text { disciplinary variations }\end{array}$ & $\begin{array}{l}\text { Aditomo, A; Goodyear, } \\
\text { P; Bliuc, AM; Ellis, RA }\end{array}$ & 2013 & 78 \\
\hline 5 & $\begin{array}{l}\text { Developing sixth graders' inquiry skills to con- } \\
\text { struct explanations in inquiry-based learning } \\
\text { environments }\end{array}$ & Wu, HK; Hsieh, CE & 2006 & 60 \\
\hline 6 & $\begin{array}{l}\text { Prompted" inquiry-based learning in the intro- } \\
\text { ductory chemistry laboratory }\end{array}$ & $\begin{array}{l}\text { Green, WJ; Elliott, C; } \\
\text { Cummins, RH }\end{array}$ & 2004 & 51 \\
\hline 7 & $\begin{array}{l}\text { The impact of the use of inquiry-based learning } \\
\text { as a teaching methodology on the development } \\
\text { of critical thinking }\end{array}$ & $\begin{array}{l}\text { Magnussen, L; Ishida, D; } \\
\text { Itano, J }\end{array}$ & 2000 & 51 \\
\hline 8 & $\begin{array}{l}\text { Where might sand dunes be on mars? Engag- } \\
\text { ing students through inquiry-based learning in } \\
\text { geography }\end{array}$ & $\begin{array}{l}\text { Spronken-Smith, R; } \\
\text { Bullard, J; Ray, W; Rob- } \\
\text { erts, C; Keiffer, A }\end{array}$ & 2008 & 49 \\
\hline 9 & $\begin{array}{l}\text { Inquiry-based learning in higher education: ad- } \\
\text { ministrators' perspectives on integrating in- } \\
\text { quiry pedagogy into the curriculum }\end{array}$ & $\begin{array}{l}\text { Justice, C; Rice, J; Roy, } \\
\text { D; Hudspith, B; Jenkins, } \\
\text { H }\end{array}$ & 2009 & 44 \\
\hline 10 & $\begin{array}{l}\text { Engaging first year students using a Web-sup- } \\
\text { ported inquiry-based learning setting }\end{array}$ & Oliver, R & 2008 & 39 \\
\hline
\end{tabular}

Tablo 1'de WoS veri tabanında ASDÖ'ye ilişkin yapılan çalışmalar içerisinde en fazla atıf alan on çalışma yer almaktadır. Tablo 1 incelendiğinde 98 atıfla 2010 yılında Spronken-Smith ve Walker tarfından yapılan çalışma olduğu görülmektedir. Bu çalışmayı takiben 94 atıfla ikinci yüksek atıfın ise 2012 yılında Levy ve Petrulis tarafından yapılan çalışmaya ait olduğu anlaşılmaktadır. Ayrıca diğer daha eski tarihli çalışmlara kıyasla 2015 yılında Hwang, Chiu ve Chen tarfından yapılan çalışmanın ise 79 atıfla üçüncü en yüksek atıfa ulaştığı görülmektedir.

ASDÖ üzerine yayın yapan en aktif ilk on dergi Tablo 2' de gösterilmiştir. 
Tablo 2. ASDÖ üzerine yayın yapan en aktif on dergi

\begin{tabular}{|c|c|c|c|}
\hline $\begin{array}{l}\text { Sira } \\
\text { No }\end{array}$ & Dergi Adı & Konu Alanı & $\begin{array}{l}\text { Yayın } \\
\text { Sayıs1 }\end{array}$ \\
\hline 1 & $\begin{array}{l}\text { International Journal of Sci- } \\
\text { ence Education }\end{array}$ & Education and Educational Research & 8 \\
\hline 2 & Research in Science Education & Education and Educational Research & 7 \\
\hline 3 & Journal of Chemical Education & $\begin{array}{l}\text { Chemistry; Education and Educational Re- } \\
\text { search }\end{array}$ & 5 \\
\hline 4 & $\begin{array}{l}\text { Journal of Science Education } \\
\text { and Technology }\end{array}$ & Education and Educational Research & 5 \\
\hline 5 & American Biology Teacher & $\begin{array}{l}\text { Life Sciences and Biomedicine - Other Topics; } \\
\text { Education and Educational Research }\end{array}$ & 4 \\
\hline 6 & Computers and Education & $\begin{array}{l}\text { Computer Science, Interdisciplinary Applica- } \\
\text { tions; Education and Educational Research }\end{array}$ & 4 \\
\hline 7 & $\begin{array}{l}\text { Journal of Baltic Science Edu- } \\
\text { cation }\end{array}$ & Education and Educational Research & 4 \\
\hline 8 & Journal of Biological Education & $\begin{array}{l}\text { Life Sciences and Biomedicine - Other Topics; } \\
\text { Education and Educational Research }\end{array}$ & 4 \\
\hline 9 & Teaching in Higher Education & Education and Educational Research & 4 \\
\hline 10 & $\begin{array}{l}\text { Eurasia Journal of Mathemat- } \\
\text { ics Science and Technology } \\
\text { Education }\end{array}$ & Education and Educational Research & 3 \\
\hline
\end{tabular}

Tablo 2'de WoS veri tabanındaki ASDÖ'ye ilişkin en çok çalışmanın yayınlandığı dergiler ve yayın sayıları yer almaktadır. Tablo 2 incelendiğinde en çok yayın yapılan ilk iki derginin 8 yayınla "International Journal of Science Education" ve 7 yayınla "Research in Science Education" olduğu görülmektedir.

ASDÖ üzerine yayınlarda en çok atıf alan dergiler ve ülkeler Tablo 3'de gösterilmiştir.

Tablo 3. ASDÖ üzerine yayınlarda en çok atıf alan dergiler ve yayınlandığı ülkeler

\begin{tabular}{llll}
\hline Sira No & Dergi Adı & Ülke & Attf Sayısı \\
\hline 1 & Studies in Higher Education & İngiltere & 192 \\
2 & Higher Education & Hollanda & 83 \\
3 & Computers and Education & İngiltere & 79 \\
4 & Studies in Higher Education & İngiltere & 78 \\
5 & International Journal of Science Education & İngiltere & 60 \\
6 & Journal of Chemical Education & ABD & 51 \\
7 & Journal of Nursing Education & ABD & 51 \\
8 & Journal of Geography in Higher Education & İniltere & 49 \\
9 & Journal for Research in Mathematics Education & ABD & 37 \\
10 & Teaching in Higher Education & İngiltere & 36 \\
\hline
\end{tabular}


Tablo 3' de WoS veri tabanındaki ASDÖ'ye ilişkin yapılan çalışmalar içerisinde en fazla atıf alan on dergi adı ve yayınlandığı ülke yer almaktadır. Tablo 3 incelendiğinde 192 en fazla atıfla "Studies in Higher Education" dergisinin diğer dergilere kıyasla öne çıktığı anlaşılmaktadır. Ayrıca ASDÖ konularında İngiltere tabanlı dergilerin atıf sayısı bakımından oldukça etkili oldukları görülmektedir.

ASDÖ çalışmalarının atıf gücü bakımından yazarlar, dokümanlar, kaynaklar, ülkeler ve üniversitelere dayalı haritalaması

ASDÖ konusunda yayınlanan çalışmalara ilişkin yapılan bibliyometrik analizler sonucunda atıfların, dökümanlara göre ağ haritası Şekil 2'de sunulmuştur.

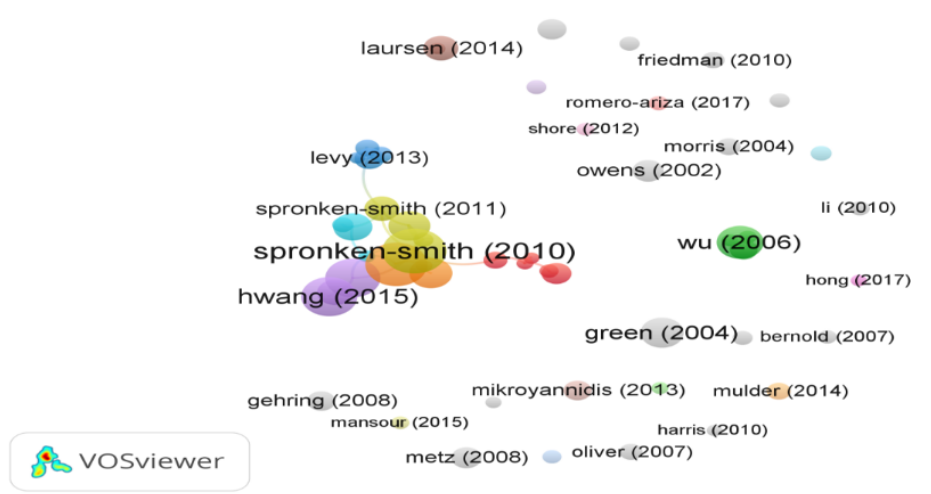

Şekil 2. ASDÖ konusunda atıflarnn dokümanlara dayalı ağ haritası

Şekil 2 ASDÖ konusundaki atıfların dokümanlara göre ağ haritası göstermektedir. $\mathrm{Bu}$ ağ haritası incelendiğinde, birçok renkte öne çıkan kümelenmelerin olduğu anlaşılmaktadır. Bu kümeler içinde bağlantı gücü en yüksek yazarların Spronken-Smith (2010) ve Hwang (2015) olduğu görülmektedir. Özellikle Sponken-Smith (2010, 2011) diğer yazarları daha fazla besleyen bir yapıya sahip olduğu anlaşılmaktadır. Bu yazarın bağlantı gücünün daha fazla olması diğer yazarlara göre çok daha fazla atıf aldığına işaret etmektedir. 
ASDÖ konusunda yayınlanan çalışmalara ilişkin yapılan bibliyometrik analizler sonucunda atıfların, kaynaklara göre ağ haritası Şekil 3'de sunulmuştur.

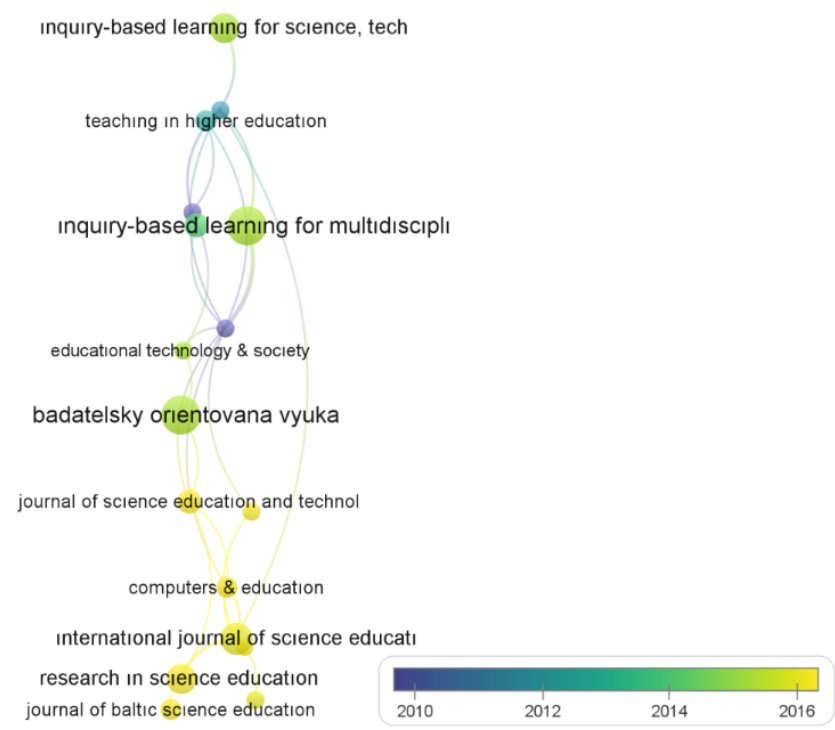

Şekil 3. ASDÖ konusunda atıflarn kaynaklara dayah ağ haritalaması

Şekil 3'de ASDÖ konusunda atıfların yıllara göre kaynaklar bakımından ağ haritası gösterilmektedir. Bu ağ haritası incelendiğinde yıllara göre alıntı sayısı bakımından özellikle 2010-2012 yılları arası "Higher Education", 20122014 yılları arasında "Studies in Higher Education", "Mathematics Education Research Journal" ve "Inquiry-Based Learning for Faculty and Institutional Development: A Conceptual And Practical Resource For Educators (Kitap Bölümü)" 2014-2016 arası "Badatelsky Orientovana Vyuka (Kitap Bölümü)" ve "Inquiry-Based Learning for Multidisciplinary Programs: A Conceptual and Practical Resource for Educators (Kitap Bölümü)", 2016 yılı sonrasında ise "International Journal of Science Education", "Journal of Science Education and Technology", "Teaching and Teacher Education" ve "Computers and Education" en fazla alıntısı yapılan kaynaklar olduğu anlaşılmaktadır. Ayrıca son yıllarda "International Journal of Science Education" kaynağının diğer kaynakları güçlü bir şekilde beslediğide görülmektedir. 
ASDÖ konusunda yayınlanan çalışmalara ilişkin yapılan bibliyometrik analizler sonucunda atıfların, yazarlara göre ağ haritası Şekil 4'de sunulmuştur.

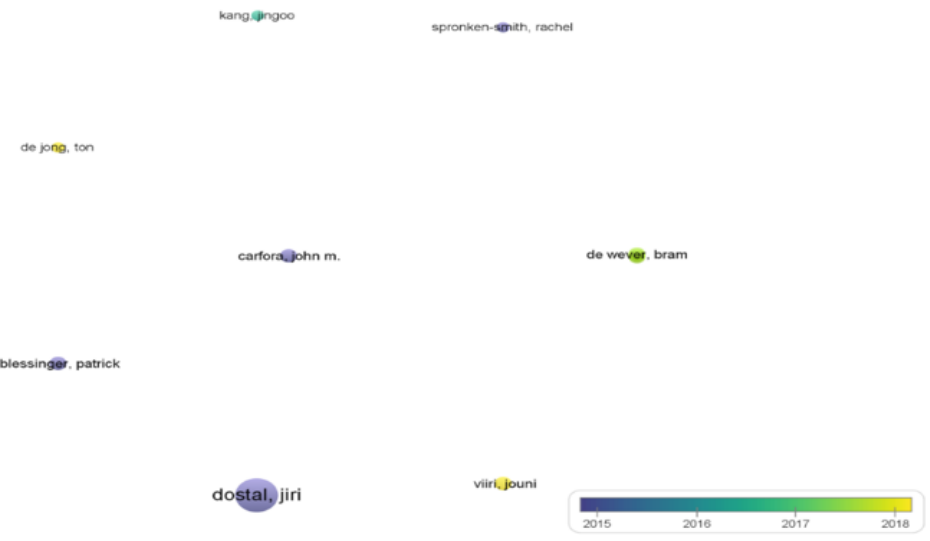

8 vosviewe

Şekil 4. ASDÖ konusunda atıfların yazarlara dayalı ă̆ haritalaması

Şekil 4'de ASDÖ konusunda atıfların yıllara göre yazarlar bakımından ağ haritası gösterilmektedir. Bu ağ haritası incelendiğinde, görsellerdeki renk uyumlarının farklılı̆̆ bu alanda öne çıkan yazarlar arasında zayıf bir ilişkinin olduğuna işaret etmektedir. Bununla birlikte atıf bakımından 2015'e kadar Dostal, Blesssinger, Carfora ve Sponken-Smith'in, 2017 sonrasinda De Wever'ın, 2018 sonrasında ise Wiiri ve De jong'un en çok tercih edilen yazarlar olduğu anlaşılmaktadır.

ASDÖ konusunda yayınlanan çalışmalara ilişkin yapılan bibliyometrik analizler sonucunda atıfların, üniversitelere göre ağ haritası Şekil 5'te sunulmuştur.

Şekil 5'de ASDÖ konusundaki atıfların üniversitelere göre ağ haritası gösterilmektedir. Bu ağ haritası incelendiğinde birçok renkte kümelenmelerin olduğu anlaşılmaktadır. Bu kümeler içinde "The University of Sheffield" ve "National Taiwan Normal University" üniversiteleri arasındaki bağlantı diğerlerine göre daha güçlüdür. Ayrıca "The University of Sheffield", "National Taiwan Normal University" ve "Palacký University Olomouc" önde gelen ve en çok atıf alan üniversitelerdir. Ayrıca haritada yer alan üniversitelerin neredeyse tamamına yakınının ASDÖ konusunda ayrı çalıştıkları anlaşılmaktadır. 


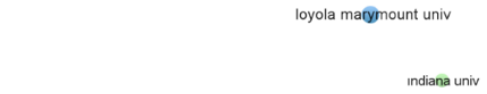

natl taiwan normal univ

univ sheffield univ palackeho olomouci

univ queensland

\& Vosviewer

Şekil 5. ASDÖ konusunda atıfları üniversitelere dayalı ağ haritalaması

ASDÖ konusunda yayınlanan çalışmalara ilişkin yapılan bibliyometrik analizler sonucunda atıfların, ülkelere göre ağ haritası Şekil 6'de sunulmuştur.

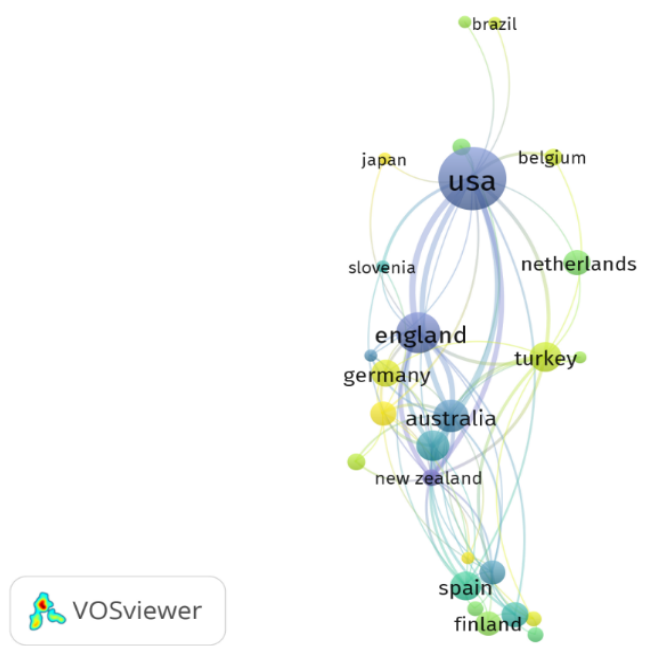

Şekil 6. ASDÖ konusunda atıflarn ülkelere dayah ağ haritalaması

Şekil 6, ASDÖ konusundaki atıfların ülkelere göre ağ haritasını göstermektedir. Bu ağ haritası incelendiğinde ASDÖ konusunda en çok katkı sağlayan kurumların ABD ve İngiltere merkezli olduğu anlaşılmaktadır. 
Ayrıca İngiltere ve Avusturalya'nın ABD ile bağlantı gücünün yüksek olduğuda görülmektedir. Bunun yanında $A B D$ ve İngiltere'nin diğer ülkeleri besleyen bir konumda olduğuda anlaşılmaktadır. Yine haritaya bakıldığında ASDÖ konusunda yayın yapan ülkelerin yıllara göre atıf sayılarında değişim görülmektedir. Özellikle 2013-2015 arası ABD, İngiltere ve Avusturalya, 2016 sonrası Almanya, Türkiye ve Finlandiya, 2018 sonrası ise Singapur kökenli yayınların öne çıktığı anlaşılmaktadır.

ASDÖ çalışmalarının bibliyografik eşleştirme bakımından yazarlar, dokümanlar, kaynaklar, ülkeler ve üniversitelere dayalı haritalaması

ASDÖ konusunda yayınlanan çalışmalara ilişkin yapılan bibliyometrik analizler sonucunda bibliyografik eşleştirmenin, dökümanlara göre ağ haritası Şekil 7'da sunulmuştur.

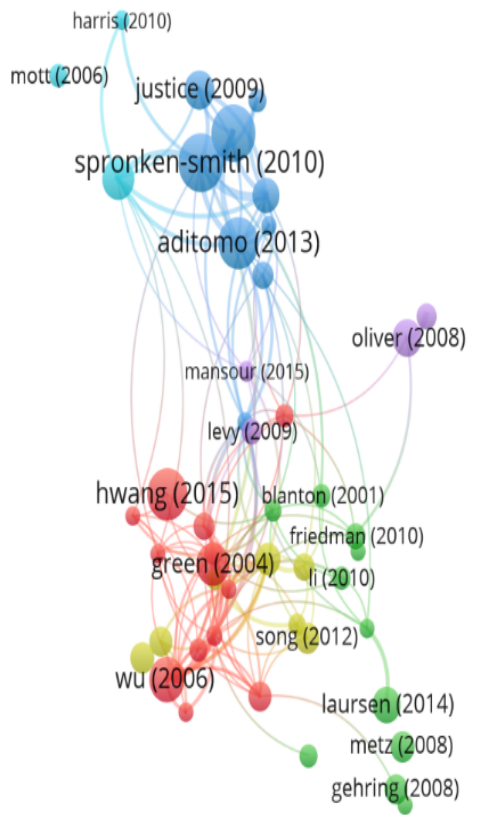

象 Vosviewer

Şekil 7. ASDÖ çalışmalarının bibliyografik eşleştirmesinin dokümanlara dayalı ă̆ haritalamast 
Şekil 7, ASDÖ konusundaki çalışmaların bibliyografik eşleştirmesinin dökümanlara göre ağ haritasını göstermektedir. Bu ağ haritası incelendiğinde dokümanlar arasında karmaşık bir ilişkinin var olduğu görülmektedir. Altı ayrı renk kümesi dökümanlar arasındaki ilişkiyi tanımlamaktadır. Bu renk kümleri incelendiğinde özellikle mavi renkleri temsil edilen dökümanların bibliyografik eşleştirme ağının daha kuvvetli olduğu anlaşılmaktadır. Harita incelendiğinde özellikle en kuvvetli bibliyografik eşleştirmenin SpronkenSmith (2010), Hwang (2015), Aditomo (2013), Wu (2006) ve Green (2004) dökümanlarında olduğu gözükmektedir.

ASDÖ konusunda yayınlanan çalışmalara ilişkin yapılan bibliyometrik analizler sonucunda bibliyografik eşleştirmenin, kaynaklara göre ağ haritası Şekil 8'de sunulmuştur.

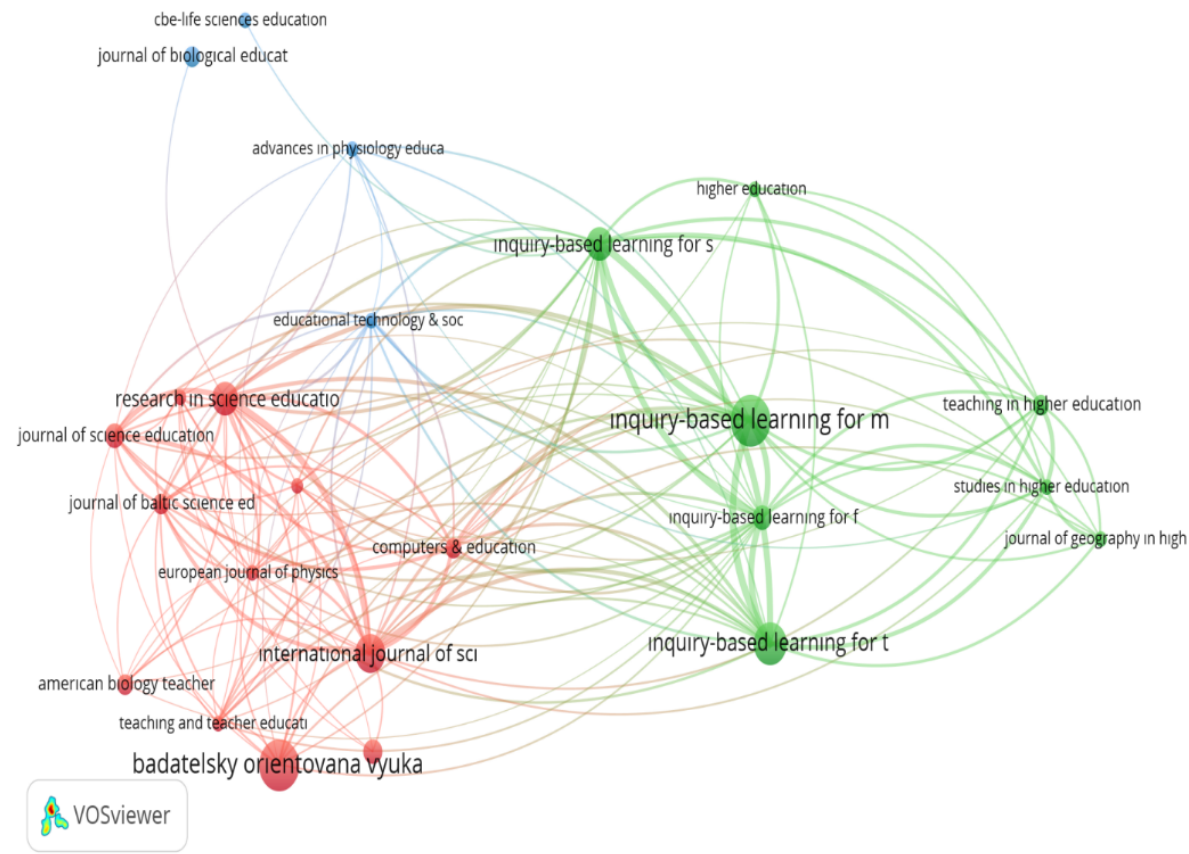

Şekil 8. ASDÖ çalışmalarnnn bibliyografik eşleştirmesinin kaynaklara dayalı ă̆ haritalaması 
Şekil 8'de, ASDÖ konusundaki çalışmaların bibliyografik eşleştirmesinin dökümanlara göre ağ haritasını görülmektedir. A $\breve{g}$ haritası incelendiğinde kaynaklar arasında üç ayrı renk içeren bağlantı kümesinin olduğu görülmektedir. Yine harita incelendiğinde en güçlü bibliyografik eşleştirmenin "Journal of Science Education and Technology", "Research in Science Education", "Inquiry-Based Learning for Multidisciplinary Programs" ve "Inquiry-Based Learning for the Arts, Humanities, and Social Sciences: A Conceptual and Practical Resource for Educators" kaynaklarında olduğu anlaşılmaktadır.

ASDÖ konusunda yayınlanan çalışmalara ilişkin yapılan bibliyometrik analizler sonucunda bibliyografik eşleştirmenin, yazarlara göre ağ haritası Şekil 9'de sunulmuştur.

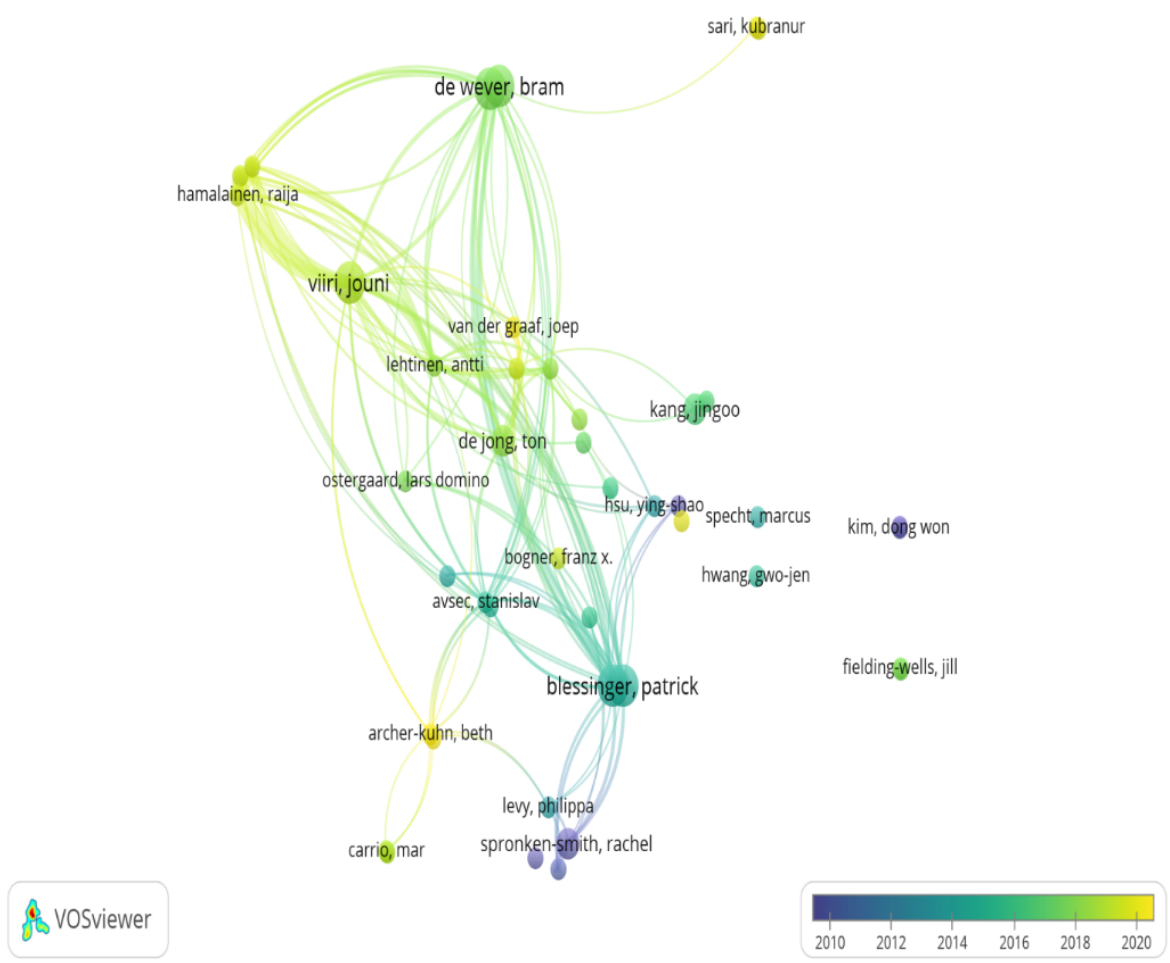

Şekil 9. ASDÖ çalışmalarının bibliyografik eşleştirmesinin yazarlara dayah ağ haritalamast 
Şekil 9'de, ASDÖ konusundaki çalışmaların bibliyografik eşleştirmesinin yazarlara göre ağ haritası yer almaktadır. Harita incelendiğinde en güçlü bibliyografik eşleştirmenin "Blessinger", “Spronken-Smith” ve De Wever isimli yazarlarda olduğu anlaşılmaktadır. Ayrıca son yıllarda bibliyografik eşleştirmenin en güçlü olduğu yazarların "Archer-Kuhn" ve "Sarı" olduğuda görülmektedir.

ASDÖ konusunda yayınlanan çalışmalara ilişkin yapılan bibliyometrik analizler sonucunda bibliyografik eşleştirmenin, üniversitelere göre ağ haritası Şekil 10'da sunulmuştur.

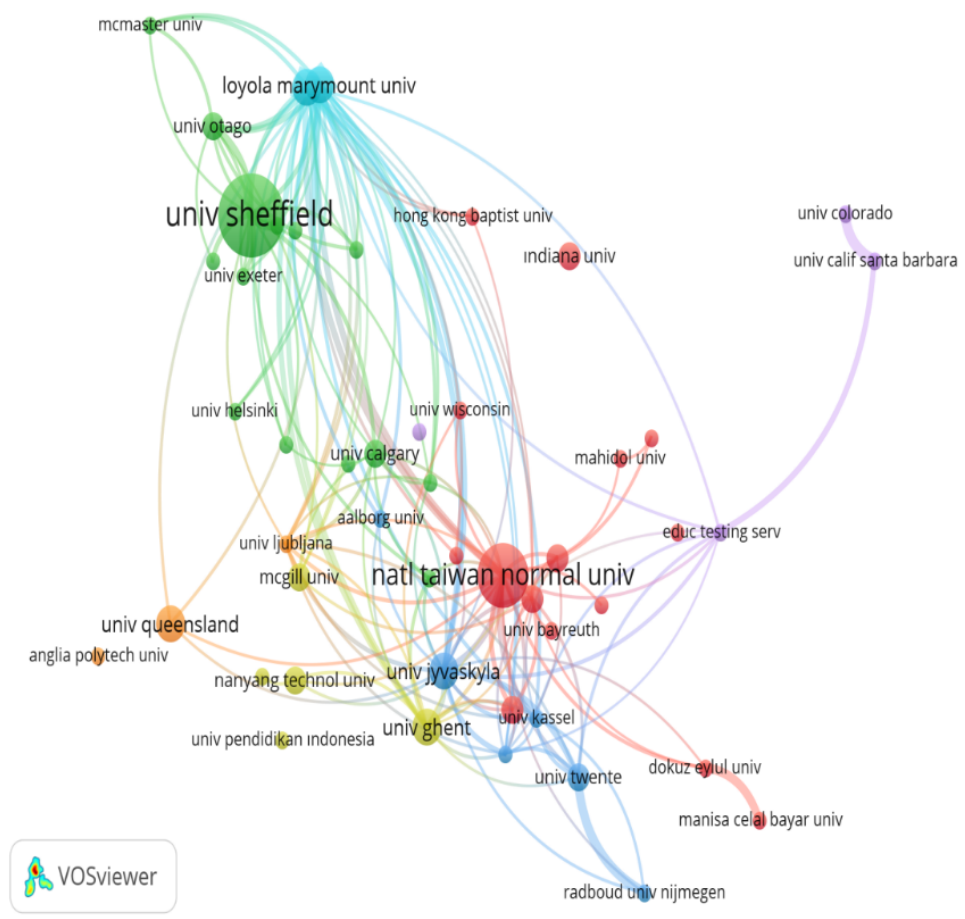

Şekil 10. ASDÖ çalışmalarının bibliyografik eşleştirmesinin üniversitelere dayalı ă̆ haritalaması

Şekil 10'da, ASDÖ konusundaki çalışmaların bibliyografik eşleştirmesinin üniversitelere göre ağ haritası yer almaktadır. Harita incelendiğinde ASDÖ konusunda "The University of Sheffield" bibliyografik eşleştirme bağı en güçlü olan üniversitedir. "The University of Sheffield" dan sonra en güçlü 
bibliyografik eşleştirmeye sahip üniversitelerin ise sırasıyla "National Taiwan Normal University" ve "Loyola Marymount University" olduğu anlaşılmaktadır.

ASDÖ konusunda yayınlanan çalışmalara ilişkin yapılan bibliyometrik analizler sonucunda bibliyografik eşleştirmenin, ülkelere göre ağ haritası Şekil 11'da sunulmuştur.

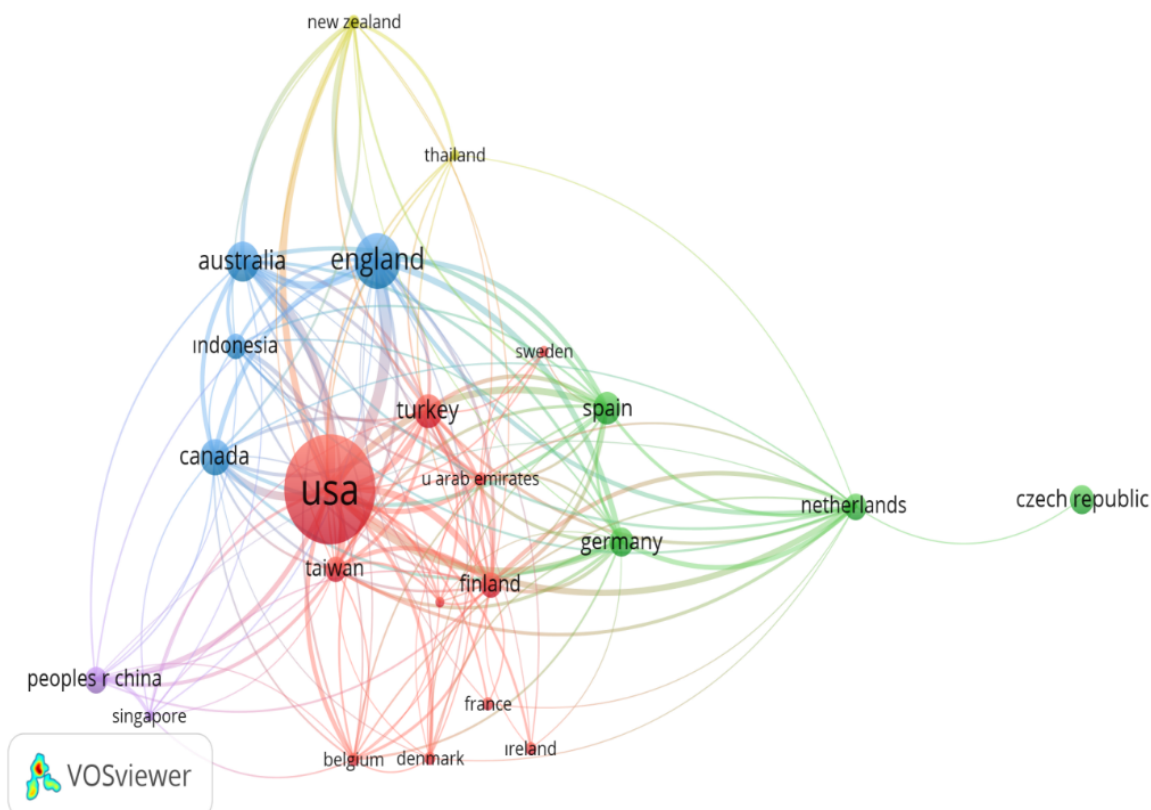

Şekil 11. ASDÖ çalışmalarının bibliyografik eşleştirmesinin ülkelere dayalı ă̆ haritalamasi

Şekil 11'da, ASDÖ konusundaki çalışmaların bibliyografik eşleştirmesinin ülkelere göre ağ haritası yer almaktadır. Harita incelendiğinde ASDÖ konusunda Amerika bibliyografik eşleştirme bağı en güçlü olan ülkedir. Ayrıca Kanada, Çin, Avusturalya, Yeni Zelanda, İngiltere, Almanya, Türkiye ve Hollanda'nın Amerika ile bibliyografik eşleşme bağının kuvvetli olduğu anlaşılmaktadır. Yine harita incelendiğinde Almanya, Hollanda ve İspanya'nın bibliyografik eşleşme bağınında kuvvetli olduğuda görülmektedir. 


\section{ASDÖ çalışmalarının ortak atıf bakımından referanslar, kaynaklar ve yazarlara dayalı haritalaması}

ASDÖ konusunda yayınlanan çalışmalara ilişkin yapılan bibliyometrik analizler sonucunda ortak atıfın, referanslara göre ağ haritası Şekil 12'da sunulmuştur.

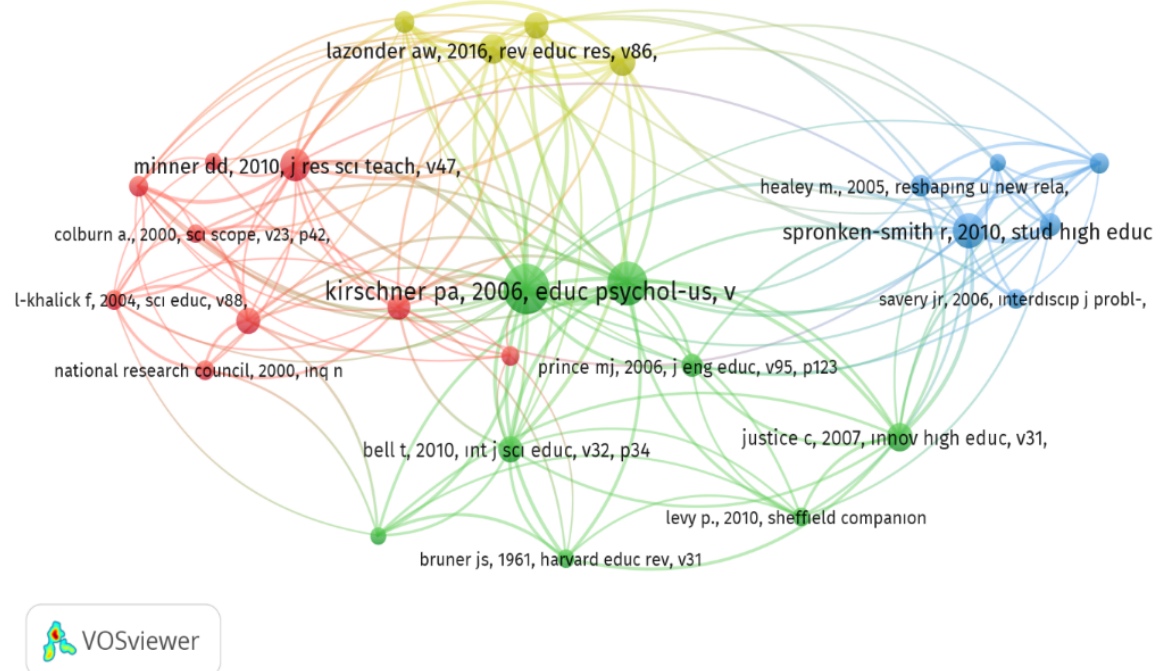

Şekil 12. ASDÖ çalışmalarnın ortak atıf bakımından alıntı yapılan referanslara dayalı ă̆ haritalaması

Şekil 12'de, ASDÖ konusundaki çalışmaların ortak atıf bakımından referanslara göre ağ haritası yer almaktadır. Bu harita incelendiğinde alıntı yapılan referanslar arasında dört farklı renkte kümelenmenin olduğu gözükmektedir. Bu kümelenmeler incelendiğinde Kirshner (2006), Spronken-Smith (2010), Justice (2007), Lazonderaw (2016) ve Minner (2010) referanslarının diğer referanslarla ortak gösterim sıklığının yüksek olduğu anlaşılmaktadır.

ASDÖ konusunda yayınlanan çalışmalara ilişkin yapılan bibliyometrik analizler sonucunda ortak atıfın, kaynaklara göre ağ haritası Şekil 13'da sunulmuştur. 


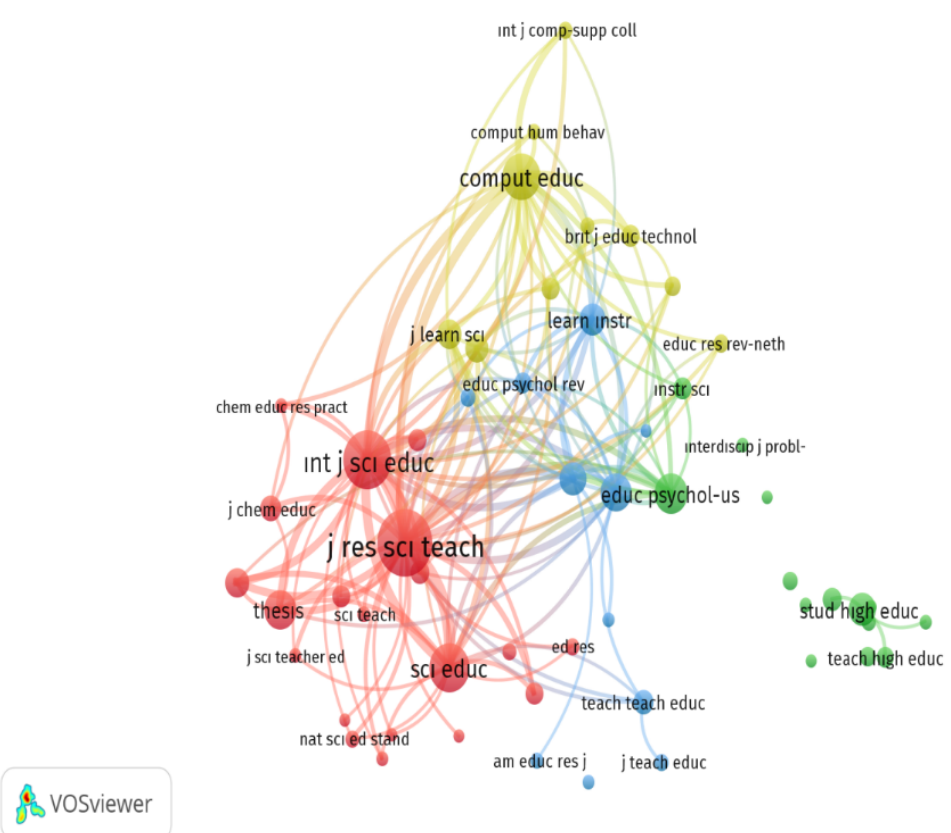

Şekil 13. ASDÖ çalışmalarının ortak atıf bakımından alıntı yapılan kaynaklara dayalı ă̆ haritalaması

Şekil 13'de, ASDÖ konusundaki çalışmaların ortak atıf bakımından kaynaklara göre ağ haritası yer almaktadır. Bu harita incelendiğinde alıntı yapılan kaynaklar arasında dört farklı renkte kümelenmenin olduğu gözükmektedir. Bu kümelenmeler incelendiğinde "Journal of Research in Science Teaching", "Computers and Education", "International Journal of Science Education", "Science and Education" ve "Studies in Higher Education" kaynaklarının diğer kaynaklarla ortak gösterim sıklığının yüksek olduğu anlaşılmaktadır.

ASDÖ konusunda yayınlanan çalışmalara ilişkin yapılan bibliyometrik analizler sonucunda ortak atıfın, yazarlara göre ağ haritası Şekil 14'da sunulmuştur. 


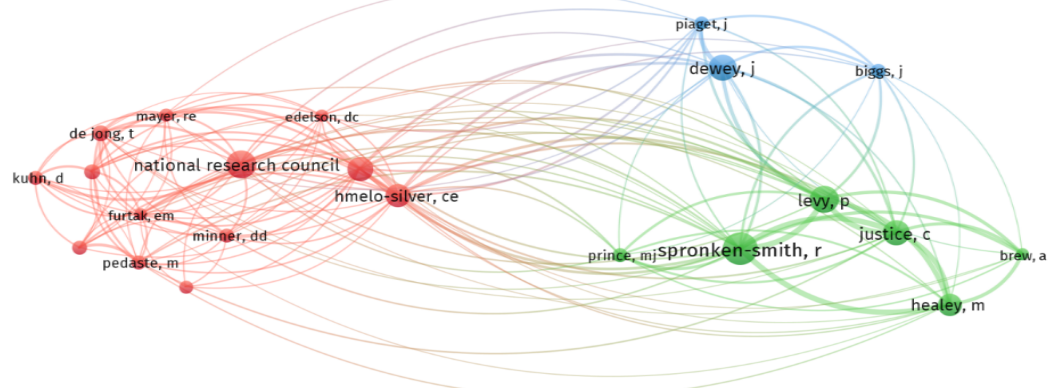

\section{sosviewer}

Şekil 14. ASDÖ çalışmalarının ortak atıf bakımından alıntı yapılan yazarlara dayalı ăg haritalaması

Şekil 14'de, ASDÖ konusundaki çalışmaların ortak atıf bakımından yazarlara göre ağ haritası yer almaktadır. Bu harita incelendiğinde ortak atıf bakımından alıntı yapılan yazarlar arasında altı farklı renkte kümelenmenin olduğu gözükmektedir. Bu kümelenmeler incelendiğinde Spronken-Smith, Justice, Dewey, National Research Council ve Hmelo-Silver yazarlarının diğer yazarlarla ortak gösterim sıklığının yüksek olduğu anlaşılmaktadır.

ASDÖ çalışmalarının ortak yazarlık bakımından yazarlar, ülkeler ve üniversitelere göre haritalaması

ASDÖ konusunda yayınlanan çalışmalara ilişkin yapılan bibliyometrik analizler sonucunda ortak yazarlı̆̆ın, yazarlara göre ağ haritası Şekil $15^{\prime}$ da sunulmuştur. 

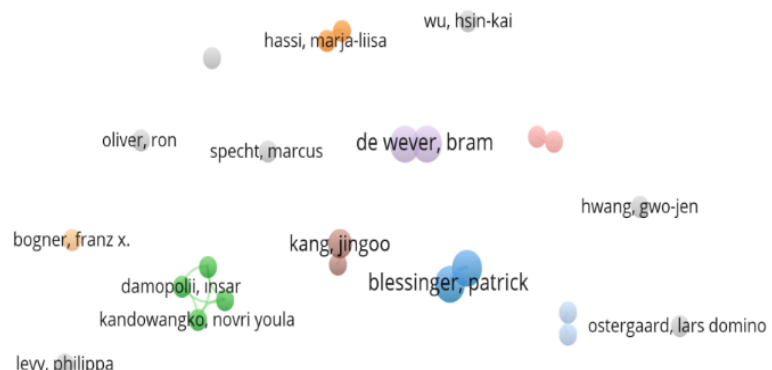

levy, philippa
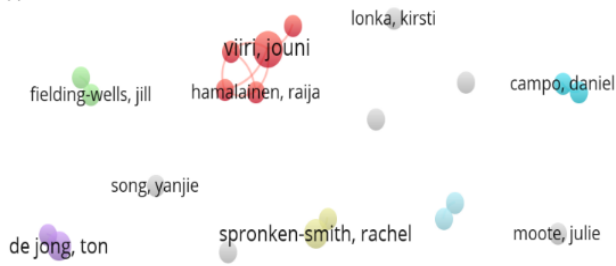

\section{串 Vosviewer}

carrio, mar

dostal, jiri

Şekil 15. ASDÖ çalışmalarının ortak yazarlık bakımından yazarlara dayalı ă̆ haritalaması

Şekil 15'de, ASDÖ konusundaki çalışmaların ortak yazarlık bakımından yazarlara göre ağ haritası yer almaktadır. Bu harita incelendiğinde ortak yazarlık bakımından Kandowangko and Damopoli, Spronken and Walker ve Virii and Hamalainen arasında güçlü bir bağın olduğu anlaşılmaktadır. Bunun dişında ASDÖ konusunda öne çıkan birçok yazarın ortak yazarlık bakımından zayıf kaldığı görülmektedir.

ASDÖ konusunda yayınlanan çalışmalara ilişkin yapılan bibliyometrik analizler sonucunda ortak yazarlığın, ülkelere göre ağ haritası Şekil 16'da sunulmuştur.

Şekil 16'de, ASDÖ konusundaki çalışmaların ortak yazarlık bakımından ülkelere göre ağ haritası yer almaktadır. Bu harita incelendiğinde ortak yazarlık bakımından Amerika, İngiltere'nin öne çıan ülkeler olduğu anlaşılmaktadır. Özellike İngiltere'nin, Yeni Zellanda, Amerika, Almanya, Çek Cumhuriyeti ile ortak yazarlık bakımından güçlü bağa sahip olduğu 
görülmektedir. Bunun yanında yine Amerika'nın İngiltere, Çin ve Yeni Zellanda ile ortak yazarlık bakımından güçlü bağa sahip olduğu anlaşılmaktadir.

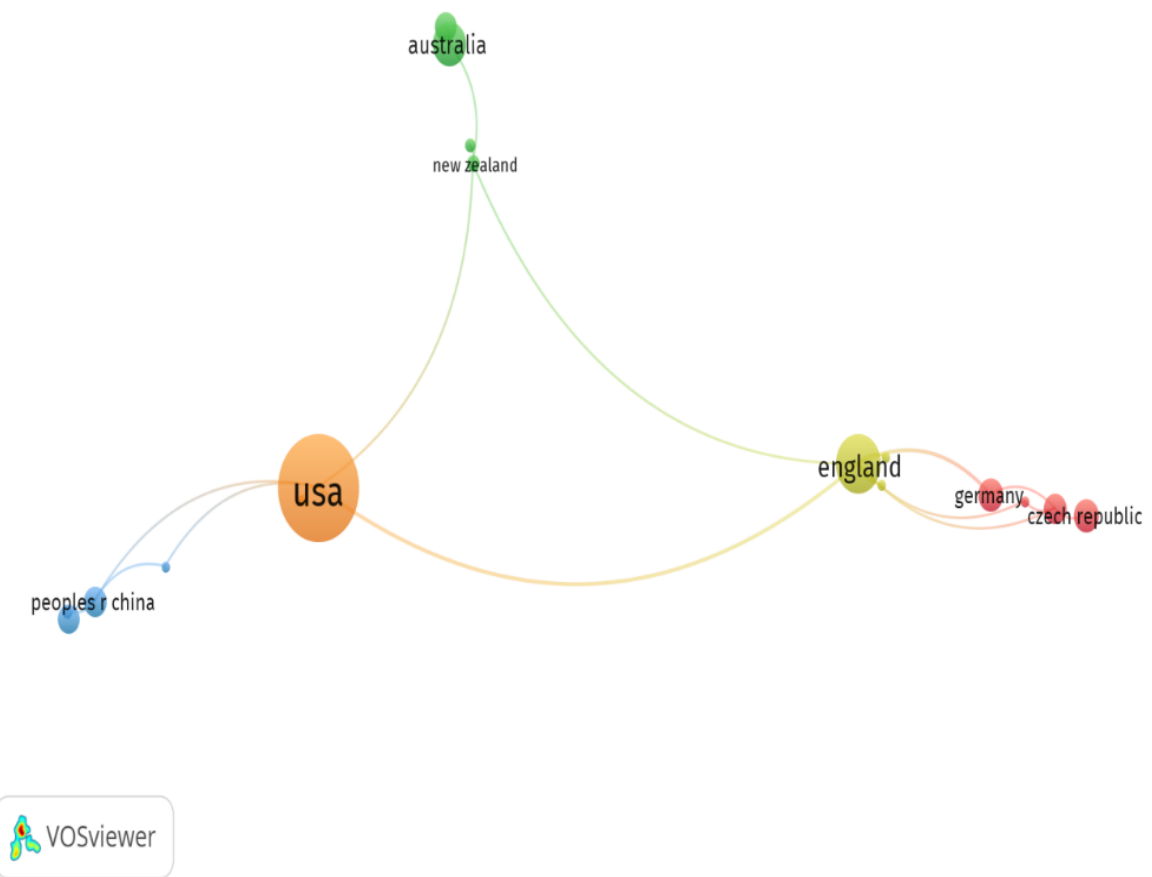

Şekil 16. ASDÖ çalş̧malarnnın ortak yazarlı bakımından ülkelere dayah ă̆ haritalaması

ASDÖ konusunda yayınlanan çalışmalara ilişkin yapılan bibliyometrik analizler sonucunda ortak yazarlığın üniversitelere göre ağ haritası Şekil $17^{\prime}$ da sunulmuştur. 


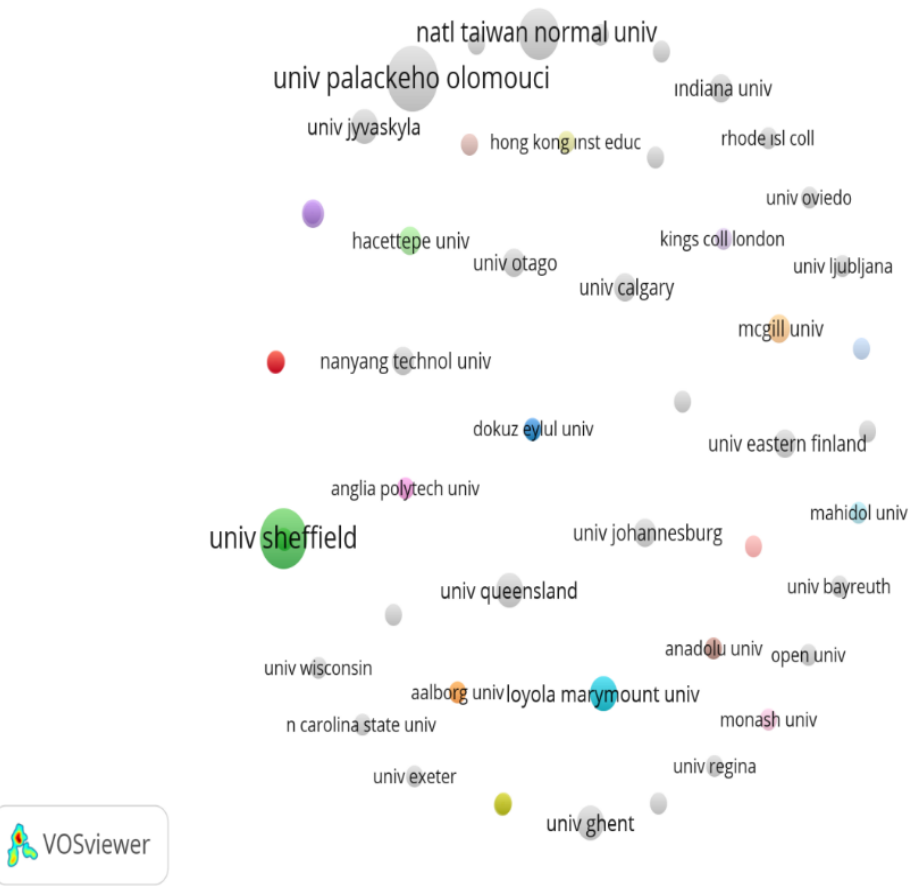

Şekil 17. ASDÖ çalışmalarının ortak yazarlık bakımından üniversitelere dayalı ă̆ haritalaması

Şekil 17'da, ASDÖ konusundaki çalışmaların ortak yazarlık bakımından üniversitelere göre ağ haritası yer almaktadır. Bu harita incelendiğinde ortak yazarlık bakımından üniversiteler arasında güçlü bir bağın olmadığı anlaşılmaktadır.

ASDÖ çalışmalarının anahtar kelime ă̆ haritalamast:ASDÖ konusunda yayınlanan çalışmalara ilişkin yapılan bibliyometrik analiz sonucunda ortaya çıkan anahtar kelime ağ yapısı Şekil 18' de sunulmuştur. 


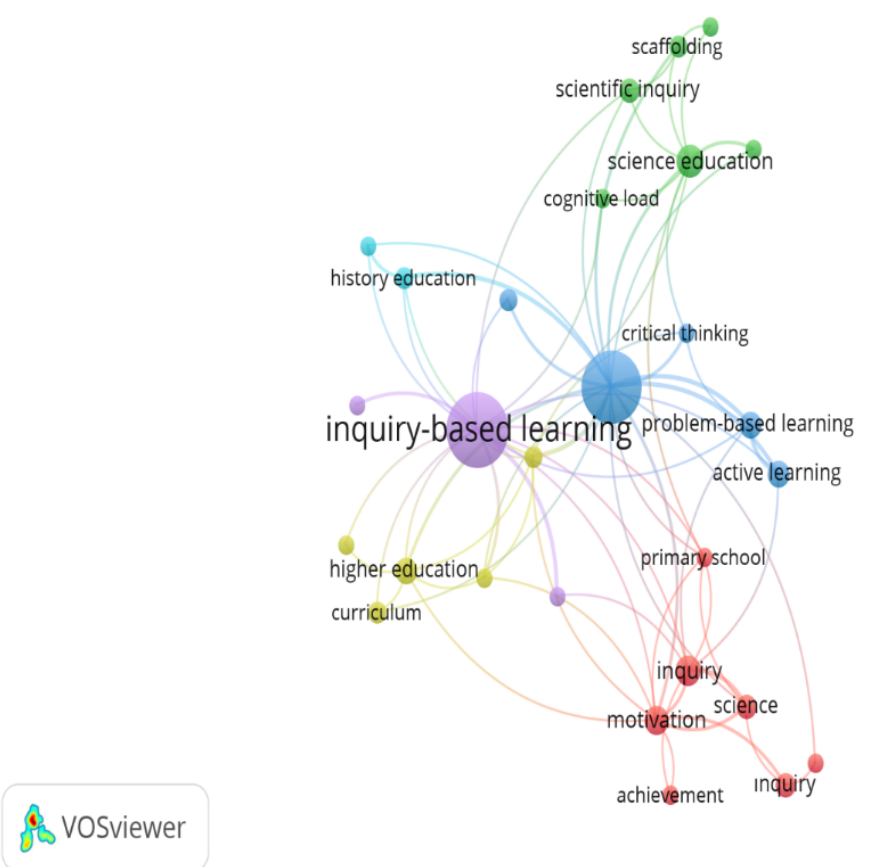

Şekil 18. Anahtar kelime ă̆ haritası

Şekil 18'de, ASDÖ konusunda ele alınan çalışmaların anhtar kelimeler ağ yapısı gösterilmektedir. A $\breve{g}$ haritası incelendiğinde anahtar kelimeler bakımından dört ayrı renkte kümelenmenin ortaya çıtığı görülmektedir. ASDÖ çalışmalarının merkezinde ve en yüksek frekansa sahip anahtar kelimenin "inquiry-based learning" olduğu anlaşılmaktadır. Ayrıca merkezilik bakımından önemli olan diğer anahtar kelimelerin ise "motivation", "active learning", "science education" "higher education" ve "inquiry" olduğu anlaşılmaktadır.

\section{Tartışma, Sonuç ve Öneriler}

Bu çalışma, Web of Science (WoS) veri tabanında yer alan 2000-2020 yılları arasındaki ASDÖ yaklaşımına yönelik yapılmış yayınların bibliyometrik analizini içermektedir. Yapılan analizler sonucunda ASDÖ çalışmalarının 2015 yılında zirve yaptığı, 2016 yılında ciddi düşüş sergilediği ve bu yıldan sonra 
yeniden istikrarlı bir yükselişe geçtiği görülmüştür. 2014 yılından öncesine göre, bu yıldan sonra bazı yıllarda yayın sayısında azalmalar olmasına karşın, ASDÖ çalışmalarının birçok ülkede hala yoğun bir şekilde çalışıldığı görülmüştür. Ayrıca ASDÖ çalışmalarının ilk dönemlerde Amerika ve İngiltere kökenli oldukları, son yıllarda ise başka coğrafyalarda daha fazla çalışılmaya başlandığı anlaşılmıştır. Bu durumların özellikle diğer ülkelerdeki öğretim programlarının ASDÖ temelli reform çalışmalarından kaynaklı olabileceği düşünülmektedir. ASDÖ konusunda yapılan yayınların atıf analizi sonucunda en çok atıf yapılan yazar Spronken-Smith ve Walker'dır. ASDÖ'ye ilişkin en çok çalışmanın yayınlandığı dergi "International Journal of Science Education", en çok atıf alan dergi ise "Studies in Higher Education'dır. ASDÖ konusunda 2010 yılında Spronken-Smith ve Walker tarafından yayınlanan çalışmanın diğer çalışmalara kıyasla öne çıkması, özelikle bu çalışmanın disiplinler arası bir araştırma olmasından kaynaklı olduğu düşünülmektedir. Ayrıca bu çalışmanın öğretim arasındaki bağı kurmada ASDÖ'nün önemini ortaya koyduğu ve bununda birçok ASDÖ çalışmasının ortak yönünü temsil ettiği söylenebilir.

ASDÖ konusundaki atıfların dokümanlara göre bibliyometrik analizi sonucunda bağlantı gücü en yüksek yazarın Spronken-Smith (2010) olduğu ortaya çıkmıştır. Atıfların kaynaklara göre analizi sonucunda özellikle son yıllarda "International Journal of Science Education" kaynağının diğer kaynakları güçlü bir şekilde beslediği anlaşılmıştır. Atıfların yazarlara göre analizi sonucunda Sponken-Smith'in en çok tercih edilen yazar olduğu anlaşılmıştır. Yine atıfların üniversitelere göre analizi sonucunda "The University of Sheffield" in önde gelen ve en çok atıf alan üniversite olduğu ortaya çıkmıştır. Ayrıca atıfların ülkelere göre analizi sonucunda ASDÖ konusunda en çok katkı sağlayan kurumların ise ABD ve İngiltere merkezli olduğu görülmüştür. Bu durum, ASDÖ çalışmalarının tarihsel süreçte ABD ve İngiltere kaynaklı olmasından kaynaklı olduğu söylenebilir. Bu iki ülke farklı ülkelere kıyasla lisanüstü eğitim yapmak amaciyla en fazla öğrenci çeken ülkelerdir. Dolayısıyla bu durumun ASDÖ'ye ilişkin çalışmaların ilk dönemlerde bu iki ülkede belirgin bir şekilde yoğunlaşmasının nedeni olduğu söyelenebilir. Daha sonra ülkelerine dönen araştırmacılar tarafından kendi ülkelerinde ASDÖ yaklaşımına yönelik yaptıları çalışmalarla öne çıktığı söylenebilir. 
ASDÖ çalışmalarının bibliyografik eşleştirmesinin dokümanlara göre analizi sonucunda en kuvvetli bibliyografik eşleştirmenin Spronken-Smith (2010), dökümanında olduğu bulunmuştur. Bibliyografik eşleştirmenin kaynaklara göre analizi sonucunda en güçlü bibliyografik eşleştirmenin "Journal of Science Education and Technology" kaynağı olduğu anlaşılmıştır. Bunun yanında bibliyografik eşleştirmenin yazarlara göre analizi sonucunda bibliyografik eşleştirmenin en güçlü olduğu yazarın "Spronken-Smith" olduğu görülmüştür. Yine üniversitelere göre analiz sonucunda bibliyografik eşleştirmenin en güçlü olduğu üniversitenin "The University of Sheffield" olduğu görülmüştür. Ayrıca ülkelere göre analiz sonucunda bibliyografik eşleştirmenin en güçlü olduğu ülkenin ise Amerika olduğu anlaşılmıştır.

ASDÖ çalışmalarının ortak atıf bakımından referanslara göre analizi sonucunda Spronken-Smith (2010) referansının ortak gösterim sıklı̆̆ının yüksek olduğu anlaşılmıştır. Ortak atıfların kaynaklara göre analizi sonucunda "Journal of Research in Science Teaching" kaynağının ortak gösterim sıklığının yüksek olduğu anlaşılmıştır. Ortak atıfların yazarlara göre analizi sonucunda ise Spronken-Smith'in diğer yazarlarla ortak gösterim sıklı̆̆ının yüksek olduğu görülmüştür.

ASDÖ çalışmalarının ortak yazarlık bakımından yazarlara göre analizi sonucunda Nusantarı and Damopoli, Laursen and Hassi, Spronken and Walker, Şaşmaz Ören ve Sarı ve Virii and Hamalainen arasındaki ortak yazarlık bağının güçlü olduğu bulunmuştur. Ayrıca ASDÖ konusunda öne çıkan birçok yazar arasında ortak yazarlık bağının zayıf kaldığı görülmüştür. Ortak yazarlık bakımından Amerika ve İngiltere'nin öne çıkan ülkeler olduğu anlaşılmıştır. Bunun yanında ortak yazarlık bakımından ASDÖ konusunda çalışan üniversiteler arasında güçlü bir bağın olmadığı anlaşılmıştır. Bu durum, ASDÖ araştırmacılarının daha çok kendi ülkelerindeki özel topluluklar ve bağlamlar içerisinde deneysel çalışmaları yapmayı tercih etmelerinden kaynaklandığı söylenebilir.

ASDÖ’ye ilişkin yayınların anahtar kelimeler yapısı bakımından analizi sonucunda çalışmaların merkezinde ve en yüksek frekansa sahip anahtar kelimenin "inquiry-based learning" olduğu görülmüştür. Araştırmaların indekslenmesi ve araştırmaya kolay ulaşılabilmesi için anahtar kelimeler çok önemlidir (Gürlen, Özdiyar and Şen, 2019). Yani anahtar kelimeler, arama motorlarının ilgili yayınları bulmasına yardımcı olan bir araçtır (Springer, 2017). Bu çalışma çerçevesinde "inquiry-based learning" anahtar kelimesinin 
öne çıkmasl, tüm alanlarda bir kalıp olarak içeriği en belirgin ve en iyi açıklayan keleme olmasından kaynaklı olduğu söylenebilir.

Sonuç olarak bu çalışma, ASDÖ konusundaki mevcut literatürden kaynak okuma ve araştırma yapmak için yukarıda belirtilen yazarlara ve dergilere odaklanma konusunda bir bakış sağlamaktadır. Çalışmamızın sonuçları, ASDÖ üzerine yapılan araştırmaların geniş bir literatür haline geldiğini göstermektedir. Özellikle son 10 yılda ASDÖ çalışmalarına artan ilgi, çeşitli coğrafyalarda çok sayıda araştırmacı işbirliğinin öne çıkmasını sağlamıştır. Bunun yanında ASDÖ konusundaki araştırmaların çoğunluğunun sınırlı sayıda ülkede gerçekleştiği görülmüştür. Yine Amerika ve İngiltere'nin ASDÖ çalışmalarında en aktif ülkeler olduğu ortaya çıkmıştır. Ayrıca Türk akademisyenlerin ASDÖ konusundaki araştırmalarını, WoS tabanlı uluslararası dergilerde yayınlayabilme konusunda zayıf kaldıklarıda görülmüştür.

Bu sonuçlar ışığında, ASDÖ konusunda yeni araştırma yapmak isteyenlerin bu alanda önde gelen Amerika ve İngiltere kaynaklı yayınları takip etmeleri önerilebilir. Bunun yanında Scopus ve ERIC gibi diğer önemli veri tabanlarında yer alan ASDÖ çalışmalarının bibliyometrik analizleride yapılarak, yeni çalışmalara yön verecek temalar etkili bir şekilde teşhis edilebilir. Ayrıca Türkiye'de ASDÖ konusunda yapılan yayınların hem nitelik hem nicel bakımından incelemesi yapılarak, WoS tabanlı dergilerde niçin yayınlanamadıkları kapsamlı bir şekilde irdelenebilir.

\section{Sinırlılıklar}

ASDÖ yayınlarına ilişkin analizlerimiz, içerik analizini içermediğinden mevcut çalışmaların niteliğini değerlendiremedik. Ayrıca bu çalışmada sadece WoS veri tabanındaki yayınlar incelenmiştir. Dolayısıyla bu alandaki önemli çalışmaları içerebilecek Scopus ve ERIC gibi veri tabanlarının incelenmemesi bu çalışmanın bir sınırlılığıdır. 
EXTENDED ABSTRACT

\section{Bibliometric Analysis of Academic Studies Regarding Inquiry-Based Teaching (2000- 2020)

\author{
Tolga Saka - Tufan İnaltekin \\ Kafkas University
}

When the studies related to Inquiry-Based Teaching (IBT) are examined, it is observed that pre-service teachers have numerous deficits in applying this approach (Arslan et al., 2014; Kapanadze et al., 2015) although this approach has many positive effects on in-service teachers, pre-service teachers, and students (Bunterm et al., 2014; Hairida, 2016; Parrish, 2017). In this regard, it can be said that the examination of studies on IBT will be an important resource for researchers who will start new studies on this subject. Unlike other studies in the literature, this study is thought to contribute to the literature from a different perspective since it has revealed the social network analysis related to IBT in the articles between 2010-2020 years. Moreover, this study allows us to read the background on IBT and identify original publications. It also demonstrates how efficient individuals, countries, and institutions related to IBT studies are. Within this scope, the study aim at conducting a bibliometric analysis of academic studies published related to IBT in the last twenty years (2000-2020).

\section{Method}

In this study, a bibliometric approach was used to explore the situation of research on IBT. Within this scope, the bibliometric method was applied for the 20-year (2000-2020) research literature on IBT, which is extracted from the Web of Science (WoS) database. The word "Inquiry-Based Learning" was searched as a keyword in the WoS database and 264 academic publications including this expression were found. 248 of these studies were in English, 11 in the Czech language, 2 in Spanish, and 3 in Turkish. In our study, VOSviewer software, free of charge, was obtained from 
www.vosviewer.com to survey the bibliography of the subject. Then, social network mapping of 264 publications was made using the VOSviewer program. In this regard, the structures of IBT studies on "citation", "bibliographic-coupling", "co-citation", "co-authorship", and "co-occurrence" network maps were revealed with regards to documents, sources, authors, institutions, and countries.

\section{Findings and Conclusion/ Discussion}

As a result of the analysis, it was observed that the studies of IBT reached a peak in 2015, showed a serious decrease in 2016, and then started a steady rise again after this year. Considering 2014 and before, although there was a decrease in the number of publications in some years after this year, it was observed that IBTstudies are still being studied intensively in many countries. Spronken-Smith and Walker are the most cited authors as a result of the citation analysis of the IBT publications. The journal with the most published studies on IBT is "International Journal of Science Education" and the most-cited journal related to IBT is "Studies in Higher Education". As a result of the analysis of the citations on IBT studies according to the universities, it was revealed that "The University of Sheffield" is the leading and most cited university. In addition, as a result of the analysis of the citations according to the countries, it was seen that the institutions that contributed to IBT studies most were located in the USA and the UK. In terms of co-authorship, it was observed that the relationship of universities working on IBT also remained weak. As a result of the analysis of the publications in terms of keywords on IBT studies, it was realized that the keyword with the highest frequency and at the center of the studies is "inquiry-based learning". The results of our study showed that researches on IBT have become a large literature. The increasing interest in IBT studies, especially in the last 10 years, has led to come to the forefront of researcher collaborations in large numbers from various geographies. In addition, it was observed that the majority of research on IBT was conducted in a limited number of countries. It was also revealed that America and England are the most active countries in IBT studies. Besides, it was observed that Turkish academics were weak in publishing their research on IBT in WoS-based international journals. 


\section{Suggestions}

Those who want to do new research on IBT can be recommended to follow the leading American and UK publications in this field. Besides this, the themes that will guide new studies can be identified effectively by making bibliometric analysis of IBT studies in other important databases such as Scopus and ERIC. Also, Why studies on IBT made in Turkey are not published in WoS based journals can be inclusively examined by investigating these studies in terms of both quantity and quality.

\section{Kaynakça / References}

Açıkgöz, D. (2019). Fen alanı öğretmenlerinin araştırma sorgulamaya dayalı öğretime yönelik tutumlarmm bazı değişkenlere göre incelenmesi. (Yayınlanmamış yüksek lisan tezi). Fen Bilimleri Enstitüsü, Amasya Üniversitesi, Amasya.

Akcanca, N. (2020). Teacher candidates' Perspectives about Applied'Basic Science in Primary Education' course. Educational Policy Analysis and Strategic Research, 15(2), 7-24. Doi:10.29329/epasr.2020.251.1

Akerson, V. L., Hanson, D. L. and Cullen, T. A. (2007). The influence of guided inquiry and explicit instruction on $\mathrm{K}-6$ teachers' views of nature of science. Journal of Science Teacher Education, 18(5), 751-772. Doi:10.1007/s10972-007-9065-4

Alkış Küçükaydın, M. (2017). Araştırma sorgulamaya dayah öğretim yaklaşımı bağlamında sinff öğretmenlerinin fen konularnndaki pedagojik alan bilgilerinin incelenmesi. (Yayınlanmamış doktora tezi). Sosyal Bilimler Enstitüsü, Amasya üniversitesi, Amasya.

Almuntasheri, S., Gillies, R. M. and Wright, T. (2016). The effectiveness of a guided inquirybased, teachers' professional development programme on Saudi students' understanding of density. Science Education International, 27(1), 16-39.

Ann Haefner, L. and Zembal-Saul, C. (2004). Learning by doing? Prospective elementary teachers' developing understandings of scientific inquiry and science teaching and learning. International Journal of Science Education, 26(13), 16531674. Doi:10.1080/0950069042000230709

Arslan, A., Ogan Bekiroğlu, F., Süzük, E. ve Gürel, C. (2014). Fizik laboratuvar derslerinin araştırma-sorgulama açısından incelenmesi ve öğretmen adaylarının görüşlerinin belirlenmesi. Türk Fen Eğitimi Dergisi, 11(2), 3-37. Doi: 10.12973/tused.10107a 
Atila, M. E. ve Sözbilir, M. (2016). Fen ve teknoloji dersi öğretim programındaki yapılandırmacılığa dayalı öğelerin öğretmenler tarafından uygulanışı: Nitel bir çalışma. Erzincan Üniversitesi Eğitim Fakültesi Dergisi, 18(2), 1418-1457. Doi:10.17556/jef.45868

Barrow, L. H. (2006). A brief history of inquiry: From dewey to standards. Journal of Science Teacher Education, 17(3), 265-278. Doi: 10.1007/s10972-006-9008-5

Basista, B., Tomlin, J., Pennington, K. and Pugh, D. (2001). Inquiry-based integrated science and mathematics professional development program. Education, 121(3), 615-624.

Bjork, S., Offer, A. and Söderberg, G. (2014). Time series citation data: The Nobel prize in economics. Scientometrics, 98(1), 185-196. Doi:10.1007/s11192-013-0989-5.

Bunterm, T., Lee, K., Ng Lan Kong, J., Srikoon, S., Vangpoomyai, P., Rattanavongsa, J. and Rachahoon, G. (2014). Do different levels of inquiry lead to different learning outcomes? A comparison between guided and structured inquiry. International Journal of Science Education, 36(12), 1937-1959. Doi:10.1080/09500693.2014.886347

Cancino, C., Merigo, J. M., Coronado, F., Dessouky, Y. and Dessouky, M. (2017). Forty years of computers and industrial engineering: A bibliometric analysis. Computers and Industrial Engineering, 113, 614-629. Doi:10.1016/..cie.2017.08.033

Chabalengula, V. M. and Mumba, F. (2012). Inquiry based science education: A scenario on Zambia's high school science curriculum. Science Education International, 23(4), 307-327.

Chan, Y. Y. (2007). Teaching queuing theory with an inquiry-based learning approach: A case for applying webquest in a course in simulation and analysis. Proceedings of FIE'O7: 37th ASEE/IEEE Frontiers in Education Conference, pages F3C-(1-6).

Chen, X., Yu, G., Cheng, G. and Hao, T. (2019). Research topics, author profiles, and collaboration networks in the top-ranked journal on educational technology over the past 40 years: a bibliometric analysis. J. Comput. Educ, 6(4), 563-585. Doi:10.1007/s40692-019-00149-1

Christensen, L.B., Johnson, R.B. and Turner, L. (2014). Research methods, design and analysis (12th ed.). Upper Saddle River: Pearson.

Chu, S., Chow, K., Tse, S. K. and Kuhlthau, C. C. (2008). Grade four students' development of research skills through inquiry-based learning projects. School $\mathrm{Li}$ braries Worldwide, 14(1), 10-37.

Çelik, K. (2012). Canllarda üreme, büyüme ve gelişme ünitesinin araştırmaya dayalı öğrenme yöntemi ile işlenmesinin öğrencilerin akademik başarılarma, bilimsel süreç 
becerilerine ve fen ve teknolojik dersine yönelik tutumlarna etkisi. (Yayınlanmamış yüksek lisans tezi). Dokuz Eylül Üniversitesi, Eğitim Bilimleri Enstitüsü, İzmir.

DeBoer, G. E. (2000). Scientific literacy: Another look at its historical and contemporary meanings and its relationship to science education reform. Journal of Research in Science Teaching: The Official Journal of the National Association for Research in Science Teaching, 37(6), 582-601.

Degenhart, H. S. (2007). Relationship of inquiry based learning elements on changes in middle school students' science, technology, engineering and mathematics (STEM) beliefs and interests (Unpublished doctoral dissertation). Texas A and M University, USA.

DiPasquale, D. M., Mason, C. L. and Kolkhorst, F. W. (2003). Exercise in inquiry: Critical thinking in an inquiry-based exercise physiology laboratory course. Journal of College Science Teaching, 32(6), 388-393.

Duran, M. (2015). Araştırmaya dayalı öğrenme yaklaşımına dayalı etkinliklerin öğrencilerin sorgulayı öğrenme becerileri üzerine etkisi. The Journal of Academic Social Science Studies, 32, 399-420.

Duru, M., K., Demir, S., Önen, F. ve Benzer, E. (2011). Sorgulamaya dayalı laboratuvar uygulamalarını öğretmen adaylarının laboratuvar algısına tutumuna ve bilimsel süreç becerilerine etkisi. Marmara Üniversitesi Atatürk Ĕ̆itim Fakültesi Eğitim Bilimleri Dergisi, 33, 25-44.

Eduan, W. and Yuanqun, J. (2019). Patterns of the China-Africa research collaborations from 2006 to 2016: A bibliometric analysis. Higher Education, 77(6), 979994. Doi:10. 1007/s10734-018-0314-6.

Eaton, J. P., Ward, J. C., Kumar, A. and Reingen, P. H. (1999). Structural analysis of coauthor relationships and author productivity in selected outlets for consumer behavior research. Journal of Consumer Psychology, 8(1), 39-59.

Fleissner, S., Chan, Y. Y., Yuen, T. H. and Ng, V. (2006, May). WebQuest markup language (WQML) for sharable inquiry-based learning. In International Conference on Computational Science and Its Applications (p. 383-392). Springer, Berlin, Heidelberg.

Franceschini, F., Maisano, D. and Mastrogiacomo, L. (2015). Influence of omitted citations on the bibliometric statistics of the major manufacturing journals. Scientometrics, 103(3), 1083-1122. Doi:10.1007/s11192-015-1583-9

Freire, R. R. and Veríssimo, J. M. C. (2020). Mapping co-creaton and co-destruction n toursm: a bibliographic coupling analysis. Anatolia, 31(4), 1-11. Doi: 10.1080/13032917.2020.1855594. 
Gürlen, E., Özdiyar, Ö. ve Şen, Z. (2019). Social network analysis of academic studies on gifted people. Education and Science, 44(197), 185-208. Doi: 10.15390/EB.2018.7735.

Hairida. (2016). The effectiveness using inquiry based natural science module with authentic assessment to improve the critical thinking and inquiry skills of junior high school students. Jurnal Pendidikan IPA Indonesia, 5(2), 209-215.

Hernández-Torrano, D. and Ibrayeva, L. (2020). Creativity and education: A bibliometric mapping of the research literature (1975-2019). Thinking Skills and Creativity, 35, 1-17. Doi:10.1016/j.tsc.2019.100625.

Hou, J., Yang, X. and Chen, C. (2018). Emerging trends and new developments in information science: A document co-citation analysis (2009-2016). Scientometrics, 115(2), 869-892. Doi:10.1007/s11192-018-2695-9.

Ireland, J., Watters, J. J., Brownlee, J. L. and Lupton, M. (2014). Approaches to inquiry teaching: Elementary teacher's perspectives. International Journal of Science Education, 36(10), 1733-1750. Doi:10.1080/09500693.2013.877618

Kahn, P. and O'Rourke, K. (2005). Handbook of enquiry and problem based learning, 1-25. http://www.nuigalway.ie/celt/pblbook/. Erişim 20.10.2020.

Kapanadze, M., Bolte, C., Schneider, V. and Slovinsky, E. (2015). Enhancing science teachers' continuous professional development in the field of inquiry based science education. Journal of Baltic Science Education, 14(2), 254-266.

Kaya, G. ve Yllmaz, S. (2016). Açı sorgulamaya dayalı öğrenmenin öğrencilerin başarısına ve bilimsel süreç becerilerinin gelişimine etkisi. Hacettepe Üniversitesi Ĕ̆itim Fakültesi Dergisi, 31(2), 300-318. DOI:10.16986/HUJE.2016016811

Kayacan, K. (2014). Öz düzenleme faaliyetleri ile zenginleştirilmiş araştırma sorgulamaya dayah öğretim stratejisinin fen bilgisi ögretmen adaylarmmn kuvvet ve hareket konusunu kavramsal anlamalarna ve akademik öz yeterliliklerine etkisi. (Yayınlanmamış doktora tezi). Gazi Üniversitesi, Eğitim Bilimleri Enstitüsü, Ankara.

Kasemodel, M. G. C., Makishi, F., Souza, R. C. and Silva, V. L. (2016). Following the trail of crumbs: a bibliometric study on consumer behavior in the Food Science and Technology field. International Journal of Food Studies, 5(1), 73-83. Doi:10.7455/ijfs/5.1.2016.a7

Kim, J. and McMillan, S. J. (2008). Evaluation of internet advertising research: A bibliometric analysis of citations from key sources. Journal of Advertising, 37(1), 99-112. 
Kowalczyk 1. D. (2003). An analysis of K-5 teachers' beliefs regarding the uses of direct instruction, the discovery method and the inquiry method in elementary science education. (Unpublished doctoral dissertation). University of Pennsylvania, USA.

Lam, J., Feng, C., Treen, E. R. and Ferreira, C. (2020). The Journal of Wine Research: A 30-year bibliographic analysis. Journal of Wine Research, 31(3), 176-193. Doi: 10.1080/09571264.2020.1816535.

Lee, O., Hart, J. E., Cuevas, P. and Enders, C. (2004). Professional development in inquiry-based science for elementary teachers of diverse student groups. Journal of Research in Science Teaching, 41(10), 1021-1043. Doi:10.1002/tea.20037

Laengle, S., Merigó, J. M., Miranda, J., Slowinski, R., Bomze, I., Borgonovo, E., and Teunter, R. (2017). Forty years of the European journal of operational research: A bibliometric overview. European Journal of Operational Research, 262(3), 803-816. Doi:10.1016/j.jor.2017.04.027

Li, J., Antonenko, P. D. and Wang, J. (2019). Trends and issues in multimedia learning research in 1996-2016: A bibliometric analysis. Educational Research Review, 28,100282. Doi: 10.1016/j.edurev.2019. 100282.

Lim, B. (2001). Guidelines for designing inquiry-based learning on the web: Online pro fessional development of educators. (Unpublished doctoral dissertation). Indiana University.

Lotter, C., Harwood, W. S. and Bonner, J. J. (2006). Overcoming a learning bottleneck: Inquiry professional development for secondary science teachers. Journal of Science Teacher Education, 17(3), 185-216. Doi:10.1007/s10972-005-9002-3

Luft, J. A. (2001). Changing inquiry practices and beliefs: The impact of an inquirybased professional development programme on beginning and experienced secondary science teachers. International Journal of Science Education, 23(5), 517-534. Doi:10.1080/09500690121307

Martí-Parreño, J., Méndez-lbáñez, E. and Alonso-Arroyo, A. (2016). The use of gamifcation in education: A bibliometric and text mining analysis. Journal of Computer Assisted Learning, 32(6), 663-676. Doi:10.1111/jcal.12161

Milli Eğitim Bakanlığı [MEB]. (2013). Talim ve terbiye kurulu başkanlĭğ ilköğretim kurumları (ilkokul ve ortaokul) fen bilimleri dersi $(3,4,5,6,7$ ve 8 . simıflar) öğretim programi. Ankara: MEB Yayınları.

Minner, D. D., Levy, A. J. and Century, J. (2010). Inquiry-based science instructionwhat is it and does it matter? Results from a research synthesis years 1984 to 2002. Journal of Research in Science Teaching, 47(4), 474-496. Doi:10.1002/tea.20347 
Murphy, C., Kilfeather, P. and Murphy, C. (2007). An exploration of issues surrounding teaching the nature of science to pre-service primary school teachers. Irish Educational Studies, 26(1), 27-38.

Nam, J., Seung, E. and Go, M. (2013). The effect of a collaborative Mentoring program on beginning science teachers' inquiry-based Teaching practice. International journal of science Education, 35(5), 815-836. Doi:10.1080/09500693.2011.584329

Ören Şaşmaz, F. ve Sarı, K., (2017). Fen eğitiminde yeni yönelimler: araştırmaya dayalı öğrenme konusunda yapılan lisansüstü tezlerin analizi. Necatibey Ĕgitim Fakültesi Elektronik Fen ve Matematik Eğitimi Dergisi, 11(2), 333-364. Doi:10.17522/balikesirnef.373412

Özdilek, Z. and Bulunuz N. (2009). The effectiveness of a guided inquiry teaching methodology on pre service teachers' science teaching self-efficacy beliefs. Journal of Turkish Science Education, 6(2), 24-42.

Pan, W., Jian, L. and Liu, T. (2019). Grey system theory trends from 1991 to 2018: A bibliometric analysis and visualization. Scientometrics, 121, 1407-1434. Doi:10.1007/s11192-019-03256-z.

Parrish, J. C. (2017). K-12 Teacher professional growth for nature of science and scientific inquiry: promoting reflection through exemplars. (Unpublished doctoral dissertation). Middle Tennessee State University, ABD.

Robertson, J., Pitt, L. and Ferreira, C. (2020). Entrepreneurial ecosystems and the public sector: A bibliographic analysis. Socio-economic Planning Sciences, 72, 1-15. Doi: 10.1016/j.seps.2020.100862

Rethinam, V. and Lynch, S. J. (2011). A multilevel analysis of a guided inquiry curriculum unit on motion and force for a diverse student population. Society for Research on Educational Effectiveness Conference, Washington.

Saka, T. (2018). 5. Sinıf Fizik Konularmm Öğretimine Yönelik Rehberli Araştırma Sorgulamaya Dayalı Öğretmen Kilavuz Materyali Geliştirilmesi ve Değerlendirilmesi. (Yayınlanmamış doktora tezi). Lisansüstü Eğitim Enstitüsü, Trabzon üniversitesi.

Saka, T., Akcanca, N., Kala Aydın, N. ve Sungur Alhan, S. (2018). The Effects of the inquiry based teaching on prospective teachers' planning and practice processes. Necatibey Faculty of Education Electronic Journal of Science and Mathematics Education, 12(1), 180-204. Doi:10.17522/balikesirnef.437735

Sarı, U., and Güven, G. B. (2013). The effect of interactive whiteboard supported inquiry-based learning on achievement and motivation in physics and views of prospective teachers toward the instruction. Necatibey Faculty of Education 
Electronic Journal of Science and Mathematics Education,7(2), 110-143. Doi:10.12973/nefmed204

Schroeder, C. M., Scott, T. P., Tolson, H., Huang, T.-Y. and Lee, Y.-H. (2007). A meta analysis of national research: effects of teaching strategies on student achievement in science in the United States. Journal of Research in Science Teaching, 44(10), 1436-1460. Doi:10.1002/tea.20212

Shah, S. H. H., Lei, S., Ali, M., Doronin, D. and Hussain, S. T. (2019). Prosumption: Bibliometric analysis using HistCite and VOSviewer. Kybernetes, 49(3), 10201045. Doi:10.1108/K-12-2018-0696

Shih, J. L., Chuang, C. W. and Hwang, G.J. (2010). An inquiry- based mobile learning Approach to Enhancing social science learning effectiveness. Educational Technology and Society, 13(4), 50-62.

Small, H. (1973). Co-citation in the scientific literature: A new measure of the relationship between two documents. Journal of the American Society for Information Science, 24(4), 265-269. Doi:10.1002/asi.4630240406

Smith, L. (1981). Citation analysis. Library Trends, 30(1), 83-106.

Soprano, K. and Yang, L. L. (2013). Inquiring into my science teaching through action research: A case study on one pre-service teacher's inquiry-based science teaching and self-efficacy. International Journal of Science and Mathematics Education, 11(6), 1351-1368. Doi:10.1007/s10763-012-9380-x

Springer. (2017). Title, abstract and keywords. https://www.springer.com/gp/authorseditors/authorandreviewertutorials/writing-a-journal-manuscript/title-abstract-andkeywords/10285522 .Erişim 25.11.2020.

Staer, H., Goodrum, D., and Hackling, M. (1998). High school laboratory work in Western Australia: Openness to inquiry. Research in Science Education, 28(2), 219-228.

Şimşek, P. ve Kabapınar, F. (2010). The effects of inquiry-based learning on elementary students' conceptual understanding of matter, scientific process skills and science attitudes. Procedia-Social and Behavioral Sciences, 2(2), 1190-1194.

Trujillo, C. M. and Long, T. M. (2018). Document co-citation analysis to enhance transdisciplinary research. Science Advances, 4(1),1-9. e1701130-e1701130. Doi: $10.1126 /$ sciadv. 1701130

Usta, Z. S. (2015). Fizik öğretmenleri için hazırlanan sorgulama temelli öğretime yönelik bir hizmet-içi eğitim programmmn etkililĭgi. (Yayınlanmamış yüksek lisans tezi). Dokuz Eylül Üniversitesi, Eğitim Bilimleri Enstitüsü, İzmir. 
Van Eck, N. and Waltman, L. (2010). Software survey: 'VOSviewer, a computer program for bibliometric mapping. Scientometrics, 84(2), 523-538. DOI 10.1007/s11192-009-0146-3

Van Eck, N. J. and Waltman, L. (2011). Text mining and visualization using VOSviewer. ISSI Newsletter, 7(3), 50-54.

Van Eck, N. J. and Waltman, L. (2014). Visualizing bibliometric networks. In Y. Ding, R. Rousseau and D. Wolfram (Eds.), Measuring scholarly impact: Methods and practice. Berlin: Springer.

Van Eck, N. J. and Waltman, L. (2017). Citation-based clustering of publications using CitNetExplorer and VOSviewer. In J. Glaser, A. Scharnhorst and W. Glanzel (Eds.), Same data-different results? Towards a comparative approach to the identification of thematic structures in science. Special Issue of Scientometrics. Doi:10.1007/s11192-017-2300-7.

Van Eck, N. J., Waltman, L., Dekker, R. and Berg, J. (2010). A Comparison of two techniques for bibliometric mapping: Multidimensional scaling and VOS. Journal of the American Society for Information Science and Technology, 61(12), 24052416. Doi:10.1002/asi.21421

Van-Uum, M. S., Verhoeff, R. P. and Peeters, M. (2016). Inquiry-based science education: Towards a pedagogical framework for primary school teachers. International Journal of Science Education, 38(3), 450-469. Doi:10.1080/09500693.2016.1147660

Waltman, L., and van Eck, N. J. (2009). A taxonomy of bibliometric performance indicators based on the property of consistency. Proceedings of the 12th International Conference on Scientometrics and Informetrics.

Varma, T., Volkmann, M. and Hanuscin, D. (2009). Preservice elementary teachers' perceptions of their understanding of inquiry and inquiry-based science pedagogy: Influence of an elementary science education methods course and a science field experience. Journal of Elementary Science Education, 21(4), $1-22$.

Vlassi, M. and Karaliota, A. (2013, October). The comparison between guided inquiry and traditional teaching method. A case study for the teaching of the structure of matter to 8th grade Greek students. 3rd World Conference on Learning, Teaching and Educational Leadership, Belgium.

Wee, B., Shepardson, D., Fast, J. and Harbor, J. (2007). Teaching and learning about inquiry: Insights and challenges in professional development. Journal of Science Teacher Education, 18(1), 63-89. Doi:10.1007/s10972-006-9031-6 
White, H. D. and McCain, K. W. (1998). Visualizing a discipline: An author co-citation analysis of information science, 1972-1995. Journal of the American Society for Information Science, 49(4), 327-355.

Wilke R. R and Straits W. J. (2005). Practical Advice for teaching inquiry-based science process skills in the biological sciences. The American Biology Teacher, 67(9), 534-540. Doi:10.2307/4451905

$\mathrm{Wu}, \mathrm{H}$. K. and Hsieh, C. E. (2006). Developing sixth graders' inquiry skills to construct explanations in inquiry-based learning environments. International Journal of Science Education, 28(11), 1289-1313. Doi:10.1080/09500690600621035

Yetisir, M. I. (2016). Guided inquiry-based physics teaching: An analysis of prospective teachers' academic achievements and views about the method. Ankara Üniversitesi Ĕ̆itim Bilimleri Fakültesi Dergisi, 49(1), 159-182. Doi:10.1501/Egifak_0000001379

Yıldız, M. (2013). Öğretim ilke ve yöntemleri (4. Baskı). Ankara: Pegem Akademi Yayincilik.

$\mathrm{Yu}, \mathrm{D}$. and Shi, S. (2015). Researching the development of Atanassov intuitionistic fuzzyset: Using a citation network analysis. Applied Soft Computing, 32, 189198. Doi:10.1016/j.asoc.2015.03.027

Zhao, X. (2017). A scientometric review of global BIM research: Analysis and visualization. Automation in Construction 80, 37-47. Doi:10.1016/j.autcon.2017.04.002.

Zeng, R. and Chini, A. A. (2017). Review of research on embodied energy of buildings using bibliometric analysis. Energy Build, 155, 172-184. Doi:10.1016/j.enbuild.2017.09.025

\section{Kaynakça Bilgisi / Citation Information}

Saka, T. ve İnaltekin, T. (2021). Araştırma-sorgulamaya dayalı öğretime yönelik akademik çalışmaların bibliyometrik analizi (2000-2020). OPUS-Uluslararası Toplum Araştırmaları Dergisi, 18(40), 2408-2449. DOI: $10.26466 /$ opus.865502. 